WALDEN

UNIVERSITY

$A$ higher degree. A higher purpose.

Walden University ScholarWorks

2016

\title{
Strategies for Accessing Credit by Small and Medium Enterprises
}

Henry Jefferson Ogoi

Walden University

Follow this and additional works at: https://scholarworks.waldenu.edu/dissertations

Part of the Finance and Financial Management Commons

This Dissertation is brought to you for free and open access by the Walden Dissertations and Doctoral Studies Collection at ScholarWorks. It has been accepted for inclusion in Walden Dissertations and Doctoral Studies by an authorized administrator of ScholarWorks. For more information, please contact ScholarWorks@waldenu.edu. 


\title{
Walden University
}

\author{
College of Management and Technology
}

This is to certify that the doctoral study by

\author{
Henry Jefferson Ogoi
}

has been found to be complete and satisfactory in all respects, and that any and all revisions required by the review committee have been made.

\author{
Review Committee \\ Dr. Beverly Muhammad, Committee Chairperson, Doctor of Business Administration \\ Faculty \\ Dr. Lynn Szostek, Committee Member, Doctor of Business Administration Faculty \\ Dr. Jamie Patterson, University Reviewer, Doctor of Business Administration Faculty
}

Chief Academic Officer

Eric Riedel, Ph.D.

Walden University

2016 


\begin{abstract}
Strategies for Accessing Credit by Small and Medium Enterprises

by

Henry Jefferson Ogoi
\end{abstract}

MBA, Saint Leo University, 2013

BSBA, Colorado Technical University, 2012

\author{
Doctoral Study Submitted in Partial Fulfilment \\ of the Requirements for the Degree of \\ Doctor of Business Administration
}

Walden University

August 2016 


\begin{abstract}
Small and medium enterprise (SME) business owners play a significant role in the Kenyan economy as they account for approximately $78 \%$ of total employment and $57 \%$ of the new jobs created. The purpose of this qualitative multiple case study was to explore what strategies some Kenyan SME business owners used within the past 5 years to access credit to improve company profitability and growth. The target population consisted of 4 SME owners of businesses located in Kakamega Town, Kenya, who have had access to credit within the past 5 years. The conceptual framework for this study was the social capital theory. Semistructured interviews were conducted and company documents were gathered. All interpretations from the data were subjected to member checking to ensure the trustworthiness of findings. Based on the methodological triangulation of the data collected, 4 themes emerged after the data analysis: (a) group lending, (b) information access, (c) education and professional background of the entrepreneur, and (d) effect of access to credit on the performance of SMEs. The application of the findings from this study may contribute to social change by providing insights and strategies for SME business owners to access credit and ensure sustainable business growth that could potentially enhance community standards of living.
\end{abstract}


Strategies for Accessing Credit by Small and Medium Enterprises

$$
\text { by }
$$

Henry Jefferson Ogoi

\author{
MBA, Saint Leo University, 2013 \\ BSBA, Colorado Technical University, 2012
}

\author{
Doctoral Study Submitted in Partial Fulfilment \\ of the Requirements for the Degree of \\ Doctor of Business Administration
}

\author{
Walden University
}

August 2016 


\section{Dedication}

I dedicate this dissertation to my family. Profound gratitude to my loving parents, Stephen and Angelina for their sacrifice to make me what I am today. I dedicate this work and give special thanks to my fiancée, Joyce Makena. Thank you for your love, moral support, and encouragement throughout my doctoral journey. You have been a source of inspiration to me. 


\section{Acknowledgements}

I would like to thank my Chairperson, Dr. Beverly Muhammad, for her encouragement, guidance, mentorship, patience and support during this process. I would also like to extend my thanks to my committee member, Dr. Lynn Szostek, and URR member, Dr. Jamie Patterson, for their guidance, inspiration, and support. You have both helped to sharpen my skills as a researcher as well as develop a qualitative doctoral study. Also, I would like to thank Dr. Freda Turner, Program Director, and Dr. Fred Walker, Doctoral Study Administrator, for their pragmatic leadership in the Doctor of Business Administration program. Your guidance and excellent mentorship have significantly contributed to my ultimate success. 


\section{Table of Contents}

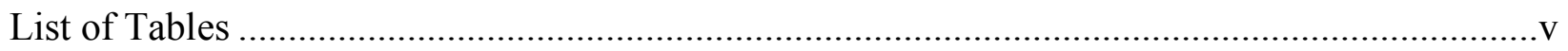

Section 1: Foundation of the Study.............................................................................

Background of the Problem ....................................................................................... 1

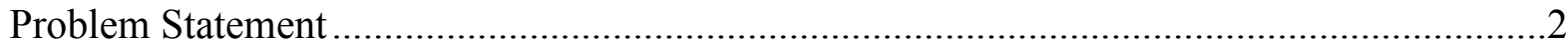

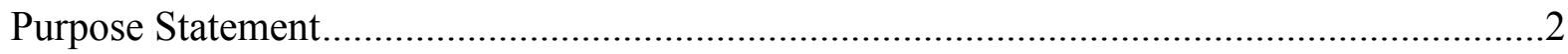

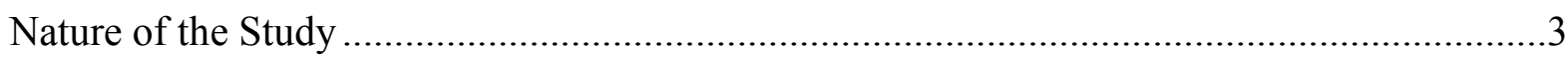

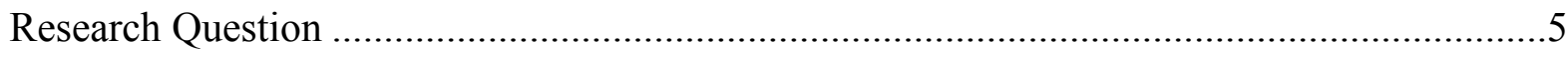

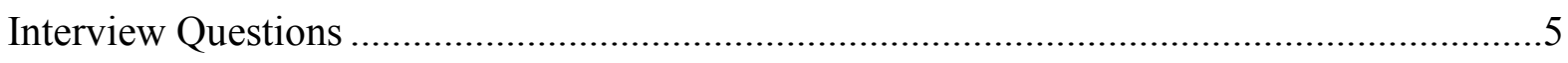

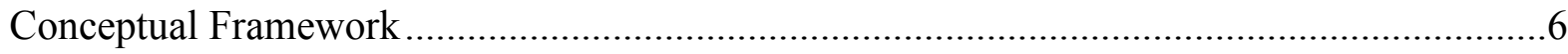

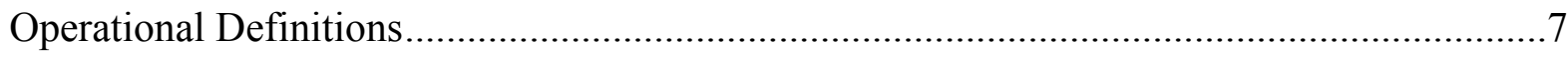

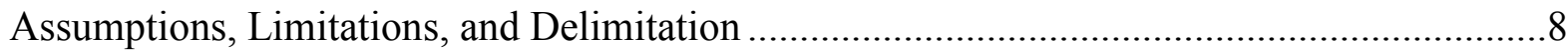

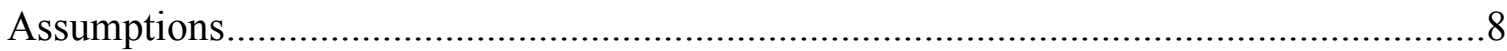

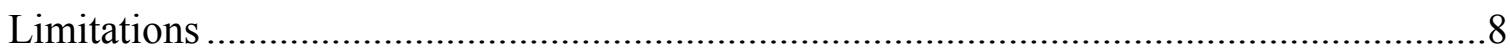

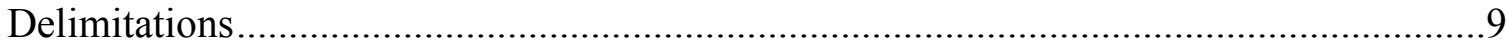

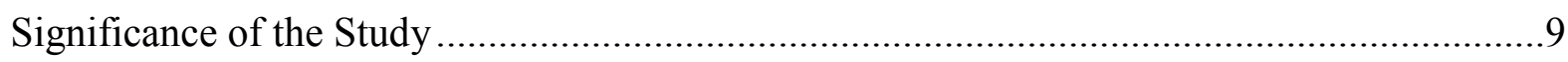

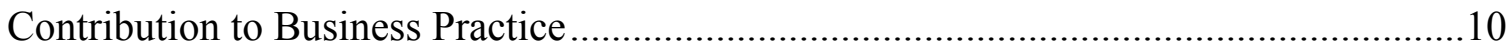

Implications for Social Change and Application for Business Practice .........................10

A Review of the Professional and Academic Literature.................................................... 10

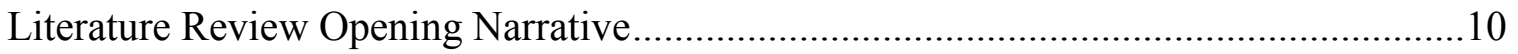

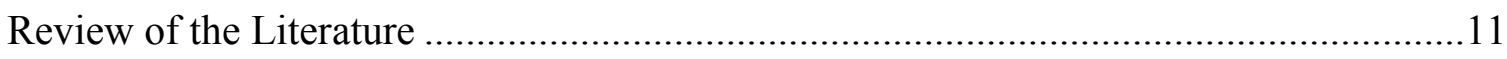

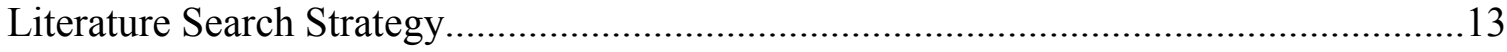




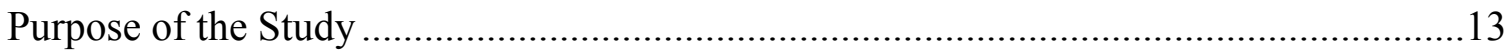

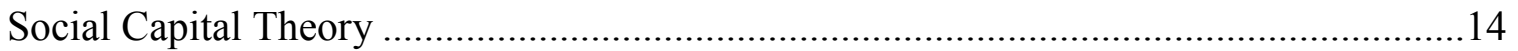

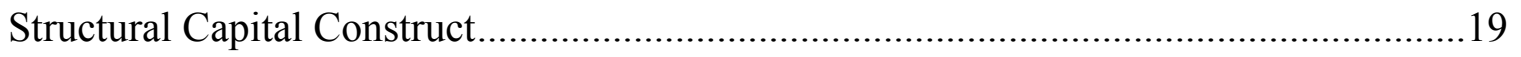

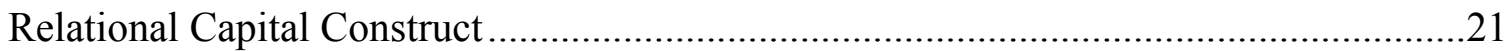

Cognitive Capital Construct..................................................................................22

Critical Analysis, Synthesis, and Compare and Contrast of Themes .............................23

Small and Medium Enterprises’' Accessibility to Credit...............................................24

Entrepreneurial Education and Training ..............................................................26

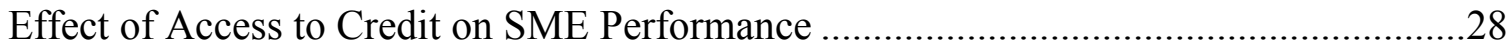

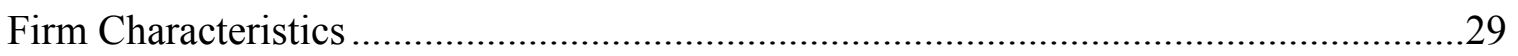

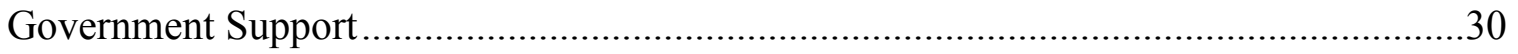

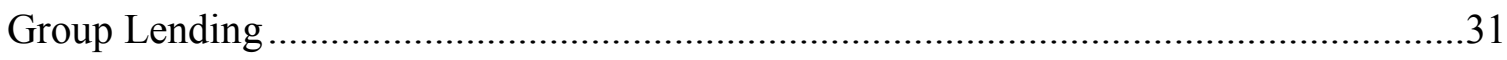

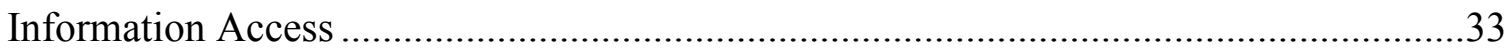

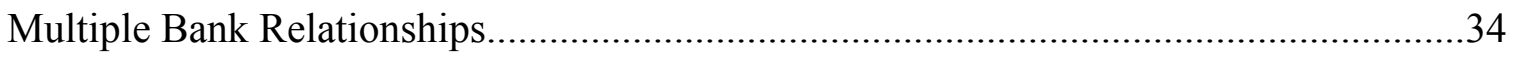

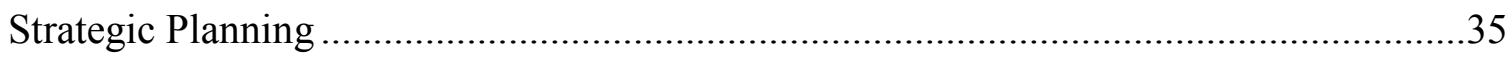

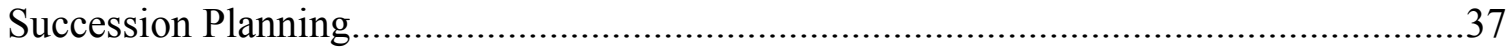

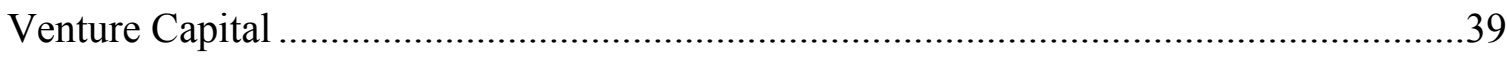

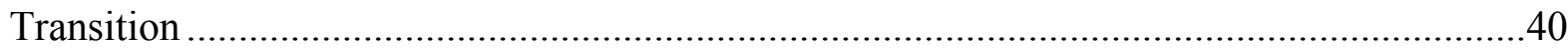

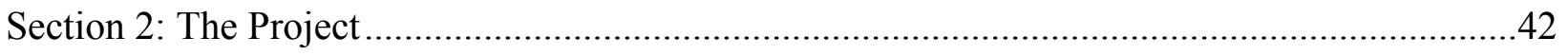

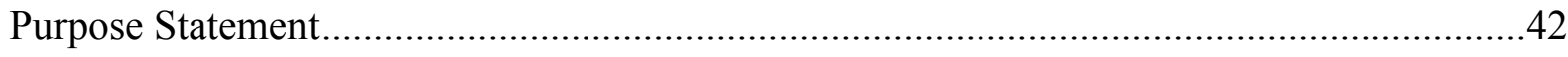

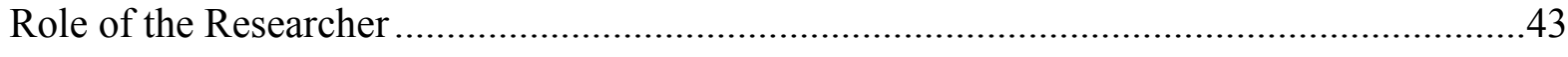

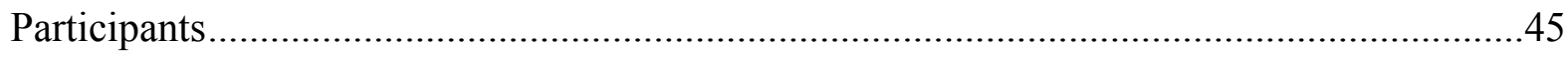

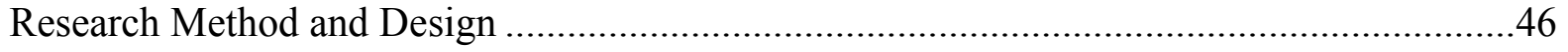




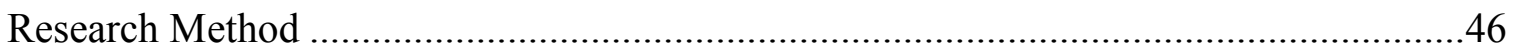

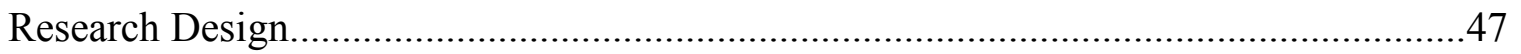

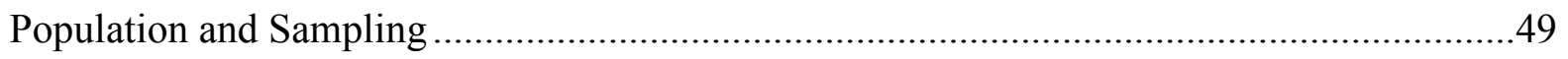

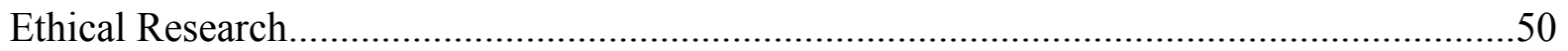

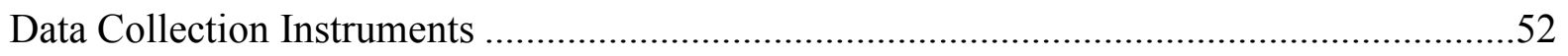

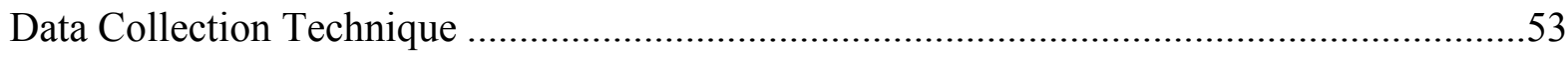

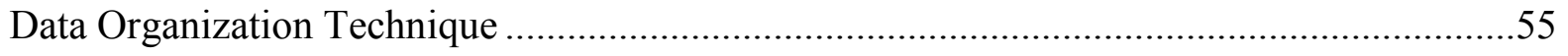

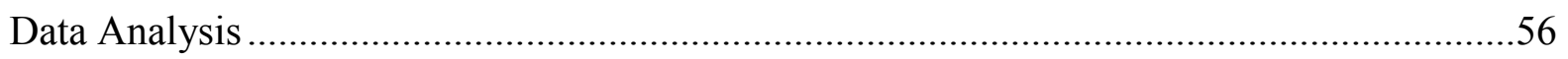

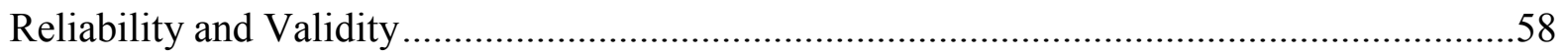

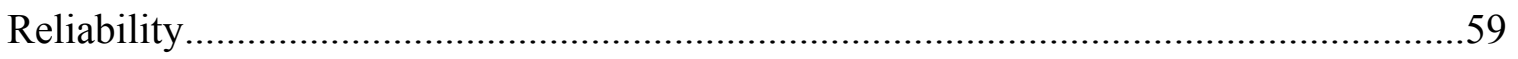

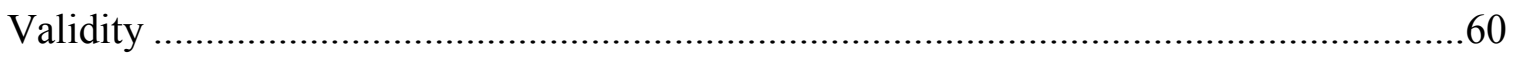

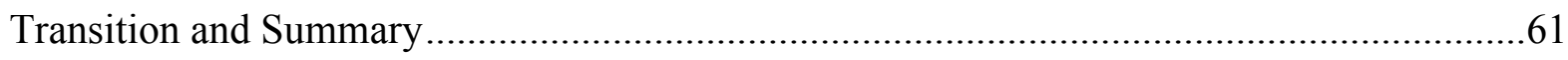

Section 3: Application to Professional Practice and Implications for Change ...............................63

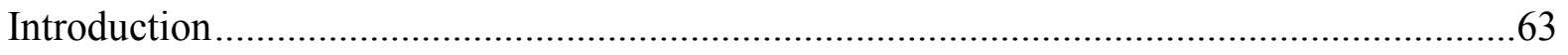

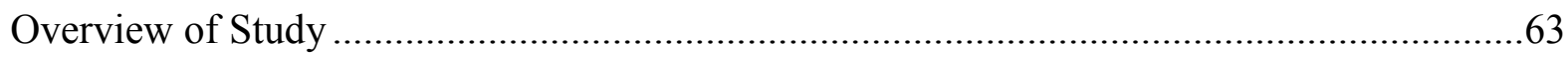

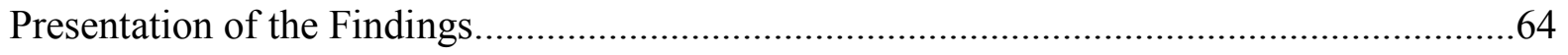

Emergent Theme: Group Lending ..............................................................................6

Emergent Theme: Education and Professional Background .............................................68

Emergent Theme: Information Access …………………….....................................

Emergent Theme: Effect of Access to Credit on Performance of SMEs............................71

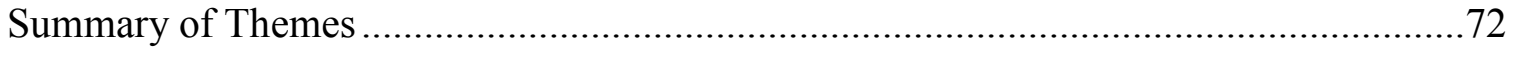

Application to Professional Practice _...................................................................................

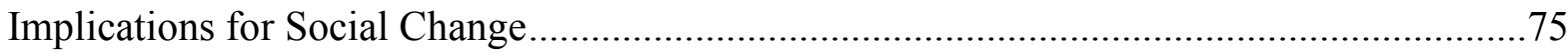




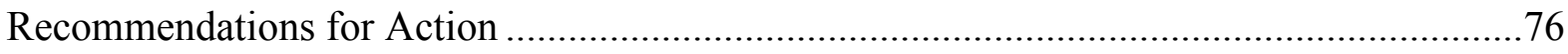

Recommendations for Further Research....................................................................... 77

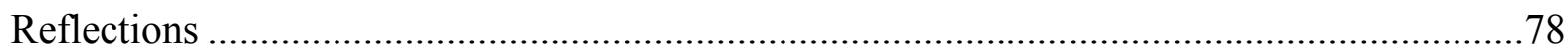

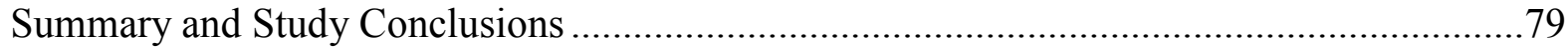

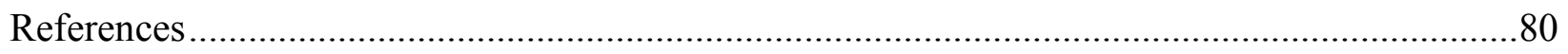

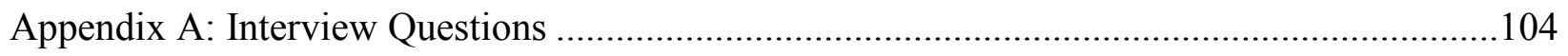

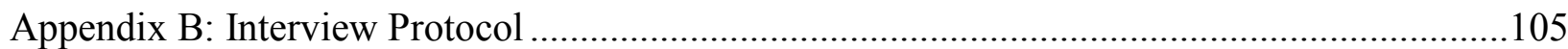




\section{List of Tables}

Table 1.Synopsis of Sources Researched in Literature Review ....................................13

Table 2.Frequency of Group Lending Strategy Mentioned ........................................68

Table 3. Educational and Professional Background of the Participants ...........................70

Table 4. Frequency of Information Access Strategy Mentioned .................................... 71

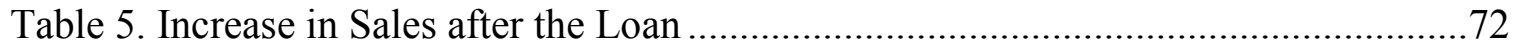




\section{Section 1: Foundation of the Study}

Small and medium enterprise (SME) business owners make a significant contribution to the economic growth of both developed and developing countries. SMEs constitute more than $99 \%$ of all enterprises in the world, allowing marginalized and vulnerable groups to diversify their incomes, generate employment opportunities, and spur economic growth (Nyamboga, Nyamweya, Abdi, Njeru, \& Gongera, 2014). Mwangi et al. (2013) found that in developing countries, formal SMEs contribute up to $40 \%$ of the private workforce and $33 \%$ of gross domestic product (GDP). These numbers indicate that SMEs are significant contributors to the economic growth of developing countries.

\section{Background of the Problem}

SME business owners have an important role in the Kenyan economy. The International Labor Organization (ILO) first epitomized the Kenya SME sector in 1972 (Nyamboga et al., 2014). Since then, this sector has been an impetus for economic growth. The SME sector contributed $78 \%$ of total employment and $57 \%$ of the new jobs created during 2005-2006 in Kenya (Kisaka \& Mwewa, 2014). SME business owners have helped to generate employment, reduce poverty, and enhance the standards of living. Despite their significant contribution, statistics indicates that SME business owners face significant challenges such as access to additional funding, which affects the performance of their businesses. The majority of SME business owners are unable to access credit because of the huge collaterals demanded by banks as a condition for lending, which constrains the growth and development of the sector. Jagongo (2012) discovered that SME business owners' inability to access credit affected the profitability and growth of their businesses. The failure to access credit may lead to financial 
constraints, and thereby affect the performance of the business. Moyi (2013) found that lack of access to financial resources contributed to the slow growth and failure of SMEs in Kenya. The purpose of this qualitative multiple case study was to explore what strategies some Kenya SME business owners used to access credit to improve company profitability and growth.

\section{Problem Statement}

The inability to access credit by SMEs is a major constraint on the business growth and development in Kenya (Mwangi \& Ouma, 2012). Eighty-five percent of Kenya SMEs are credit constrained and cannot afford the collateral demanded by banks that may be valued up to $200 \%$ of the loan (Moyi, 2013 Mwangi, Shisia, Mwai, \& Okibo, 2014). The general business problem is that the inability of some Kenya SME business owners to access credit and the limitations this has on business profitability and growth (Njeru, 2014). The specific business problem is that some Kenya SME business owners lack strategies to access credit to improve company profitability and growth.

\section{Purpose Statement}

The purpose of this qualitative multiple case study was to explore what strategies some Kenya SME business owners used to access credit to improve company profitability and growth within the past 5 years. The target population consisted of four

Kenya SME owners of businesses located in Kakamega Town, Kenya, and who have had access to credit to improve company profitability and growth. Face-to-face semistructured interviews with four SME business owners ensured data saturation. Data saturation is the point at which no additional themes are found from the reviewing of successive data regarding the phenomenon (Ando, Cousins, \& Young, 2014). To achieve 
data saturation, I continued interviewing until no new themes emerged. Additionally, an examination of each business owner's company documents in the form of monthly cash flow and profit and loss statements was supplemental data for analysis. The data from this study might affect social change by contributing to SME business owners accessing credit to ensure sustainable business growth that could potentially enhance community standards of living.

\section{Nature of the Study}

Qualitative research methods allow researchers to study social phenomena, situations, and processes that involve people, illuminating them from a variety of perspectives (Hazzan \& Nutov, 2014). In this study, I used a qualitative multiple case study design approach to explore what strategies some Kenya SME business owners used to access credit to improve company profitability and growth.

Qualitative inquiry means staying inductively open to the unknown while exploring and seeking to enhance a deeper understanding of the social phenomena (Kaczynski, Salmona, \& Smith, 2013). A qualitative research method provides the researcher with a framework for obtaining an in-depth understanding of the problem from the participants' perspective. The nature of this study aligns with the qualitative research method more than the quantitative method because of the exploratory nature of the topic. Anyan (2013) argued that quantitative research methods focus on numerical data expressions and volume of data collected. Therefore, I did not use quantitative or mixed methods because the purpose of the study was to obtain a deeper understanding of the phenomenon, and not statistical information. 
Qualitative research designs include case study, narrative, ethnography, and phenomenology. For this study, I used the case study design method to explore what strategies some Kenyan SME business owners used to access credit for their businesses. The case study design is an exploration of a bound system through in-depth data collection, each study with its particular sampling and analysis strategies (Boblin, Ireland, Kirkpatrick, \& Robertson, 2013). The case study design allows the researcher to obtain a better understanding of a specific or complex social problem through interview, observation, and documentation (Petty, Thompson, \& Stew, 2012). The design is the logical sequence used to connect the empirical data to a study's initial research questions and its conclusions (Yin, 2014). Additionally, using an exploratory case study design, I asked the why and what of the study to obtain an in-depth understanding of the phenomenon. I did not use narrative research, ethnography, or phenomenology because they do not provide an in-depth understanding of the problem. Narrative research focuses on the detailed stories or personal reflection of events from one or more individuals (Petty et al. 2012). The intent of this study was to understand the strategies Kenyan SME business owners used to obtain credit and not personal stories. I did not use ethnography because it contains guidance for capturing the cultural aspects of the research participants and not business problems. Ethnography contains instructions the researcher can use to examine the shared patterns of behavior, beliefs, and language within a cultural group (Petty et al., 2012). Researchers use phenomenological design to capture the worldviews and lived experiences of individuals relevant to the phenomenon (Moustakas, 1994). I did not select the phenomenological design because I was not studying the worldviews and lived experiences of individuals. The focus of this study was to explore what 
strategies some Kenyan SME business owners used to access credit to improve company profitability and growth, and not the lived experience of individuals.

\section{Research Question}

The overarching research question for this study was: What strategies do some Kenyan SME business owners use to access credit to improve company profitability and growth? The answer to this question was a critical goal for this research study. Makena, Kubaison, and Njati (2014) found that SMEs were unable to access credit, which affected their profitability and growth, because of collateral demands.

\section{Interview Questions}

The following were the interview questions (Appendix A) for this qualitative multiple case study. Questions 1-6 are concept questions, and Question 7 is the wrap-up question.

1. What strategies do you use to access credit for your business?

2. What are the main challenges to accessing credit for your business?

3. How does your relationship with other SME business owners help you obtain credit for your business?

4. How would you describe your relationship with the banks?

5. How does access to information help you obtain credit for your business?

6. How does accessibility to credit affect the performance of your business?

7. What else would you like to share about your experience of how to access credit for your business? 


\section{Conceptual Framework}

The conceptual framework for this study is the social capital theory (SCT) developed by Hanifan in 1916. Hanifan described social capital as those intangible substances that count most in the daily lives of people, namely, goodwill, fellowship, mutual sympathy, and social interaction among members of a social unit. Hanifan explained how members of the rural school community used their social capital to help improve the school performance. Although the theory was not business related, later several theorists extended the works of the Hanifan (Nahapiet \& Ghoshal, 1998; Woolcock \& Narayan, 2000; Mwangi \& Ouma, 2012). Specifically, they used the theory to explain how poor people accumulate their social capital to achieve a common purpose.

The constructs underlying the theory are (a) structural capital, (b) relational capital, and (c) cognitive capital. Nahapiet and Ghoshal (1998) developed three constructs of the social capital theory to describe how firms facilitate the combination and exchange of resources to achieve a common goal. Nahapiet and Ghoshal defined the structural construct of the social capital theory as the pattern of connections between actors to achieve a common goal. They described the relational construct of the social capital theory as the resources created and leveraged through personal relationships. In addition, Nahapiet and Ghoshal defined the cognitive construct of social capital theory as the resources providing shared representation, interpretation, and systems of meaning among the parties. The social capital theory is applied to this research because the three constructs allowed me to obtain an in-depth understanding of the strategies some Kenyan business owners use to access credit to improve company profitability and growth.

People who have a shared vision, language, norms, values, and systems tend to trust each 
other by working together to meet the obligations imposed by others. In developing countries, poor borrowers who have no collateral assets use social capital to establish social networks to help access credit to sustain their businesses (Woolcock \& Narayan, 2000). Kenya is among the developing countries with majority rural and urban borrowers who have no collateral assets to gain access to credit to improve the profitability and growth of their businesses (Mwangi \& Ouma, 2012).

\section{Operational Definitions}

Access to finance: The ability of a firm's designated personnel or owner to obtain and use financial services that are affordable, usable, and meet their financial needs (Musamali \& Tarus, 2013).

Collateral: An economic asset or security that enables a firm's personnel or owner to secure bank loans (Mwobobia, 2012)

Financial constraints: Internal and external factors that prevent a firm's designated personnel or owner from funding all desired investments (Onyango \& Achieng, 2013).

Group lending: A credit system that addresses the problems of screening, incentives, and enforcement by incorporating joint liability principle and peer monitoring (Naveen, 2012).

Information asymmetry: Lack of quality information that limits a firm from obtaining external finance because of high transaction costs (Njeru, Nyangaresi, \& Waithaka, 2013).

Multiple banking: Diverse banking relationships that help financially constrained firms to access credit (Shikimi, 2013). 
Social capital: Mechanisms that help a firm to access information and exploit opportunities to achieve a sustainable competitive advantage (Kontinen \& Ojala, 2012).

Strategic planning: A framework that helps a firm measure and evaluate its progress by directing and controlling its business activities (Awino, 2013).

Succession planning: Business strategies used by owners or managers to propose and mentor a successor to ensure the survival of the firm after the retirement or death of first generation entrepreneur (Karanja, 2012).

Venture capital: A nonbank financing source that provides funding to new or existing firms with the potential for above-average growth (Jagongo, 2012).

\section{Assumptions, Limitations, and Delimitation}

\section{Assumptions}

Assumptions are facts considered true but not verifiable. Assumptions are somewhat out of the researcher's control, but if they disappear, the study becomes irrelevant (Simon \& Goes, 2013) There were several assumptions in this study. I assumed that (a) participants would answer the questions honestly (b) willingly share business documents, and (c) that business documents would be comprehensive. Availability of accurate and unbiased documents helps to corroborate and augment evidence from interviews (Yin, 2014).

\section{Limitations}

Limitations are potential weaknesses of the study. According to Simon and Goes (2013), limitations are occurrences that arise in a study that are beyond the researcher's control. The potential weakness of this study related to obtaining documentation data from the participants. In Kenya, SME owners thend to keep their business information 
private, specifically financial information for fear of rivals gaining a competitive edge. However, I tried to reduce this resistance to sharing business information to enhance validity and reliability of the data. The use of different procedures for collecting data helps enhance the dependability and trustworthiness of the data and their interpretation (Zohrabi, 2013) Another limitation was the possibility of participants withdrawing from the study without prior notice, which could affect the research process.

\section{Delimitations}

Delimitations are characteristics that limit the scope and define the boundaries of the study(Simon \& Goes, 2013). The delimitations of this study included the geographical location. The geographical location for this study included only SME business owners in Kakamega Town, Kenya. I might have chosen a different geographical research site, but Kakamega Town was the best fit for this study. The focus of the study was SMEs whose business owners have had access to credit to improve company profitability and growth. Kenyan SME business owners were the main source of data for this study. Therefore, another delimitation was that I did not collect data from the employees of SMEs.

\section{Significance of the Study}

This study was significant in that I explored the strategies that some SME business owners used to access credit to improve company profitability and growth within the past 5 years in Kakamga Town, Kenya. The Walden University requires all DBA students to conduct their studies with implications for positive social change. The data collected may contribute to the body of entrepreneurial knowledge to benefit both the current and future business owners in the SME sector. Additionally, the findings may 
contribute to positive social change by allowing SME business owners and managers ensure long-term sustainable growth, generate employment, reduce poverty, and enhance standards of living.

\section{Contribution to Business Practice}

The study helped to solve a problem by exploring the strategies SME business owners used to access credit to improve company profitability and growth. Previous studies contained the notions that majority SMEs face constraints in accessing credit despite their significant contribution to the Kenyan economy (Kisaka \& Mwewa, 2014; Ijaza, Mwangi \& Ng'etich, 2014). The findings of this study may help business owners to make sound financial decisions on how to access funding to improve the growth and development of the SME sector. The data collected from this study may be useful to the business owners, creditors, and the relevant government agencies to understand the challenges that SMEs face in accessing credit.

\section{Implications for Social Change and Application for Business Practice}

The implications for positive social change include the potential for SME business owners to share best practices for improving access to credit and ensure sustainable growth to enhance standards of living. Additionally, community change agents and the government may use these findings to formulate new policies for promoting the growth of the SME sector, which affect a positive social change.

\section{A Review of the Professional and Academic Literature}

\section{Literature Review Opening Narrative}

This section comprises the organization of the review, literature search strategy, summary of frequencies and percentages of peer-reviewed and scholarly articles, the 
purpose of the study, and critical analysis and synthesis of the literature pertaining to the conceptual framework, as well as critical analysis and synthesis of the literature related to potential themes identified in the purpose statement and comparing and contrasting the relationships of previous research findings.

The purpose of the professional and academic literature search was to explore published literary works related to the doctoral research topic. The review of this academic literature was an essential requirement of this qualitative multiple case study that particularly concerned the strategies that SME owners used to access credit for their businesses. This review of the literature contained information about the purpose of the study that related to the research question: What strategies do some Kenya SME owners use to access credit to improve company profitability and growth? Evidence from the review of the literature findings included lack of collateral, strategic planning, financial literacy, and poor access to information as some of the major constraints on SMEs' accessibility to credit. The rationale for this doctoral study, therefore, was to explore the successful strategies that some Kenyan SME business owners used to access credit.

\section{Review of the Literature}

Literature reviews help researchers (a) identify the literature that will contribute to the research study, (b) build an understanding of the topic, (c) formulate a conceptual framework for the study, and (d) understand how to collect and analyze data (Rowley, 2012). The literature review in this study comprised information from various authors whose findings are similar and dissimilar regarding SMEs' accessibility to credit. The critical analysis and synthesis of the literature depict an in-depth understanding of the extent of the problem concerning accessibility to credit by SMEs. 
For this study, I obtained the sources mainly from searching business and management databases within the Walden University Online Library. The databases I used in the literature search included Academic Search Complete, ProQuest, ScienceDirect, Emerald Management Journals, Business Source Complete, Sage Premier, and Multidisciplinary, along with relevant books and websites. The literature sources included scholarly and peer-reviewed articles, dissertations, conference proceedings, seminal and contemporary books, and websites. Table 1 contains a synopsis of sources researched to complete this literature review indicated there were 164 total sources, of which $92.07 \%$ were peer-reviewed. Over $86.59 \%$ comprised the peer-reviewed articles published after 2011. The peer-reviewed sources included journal articles, dissertations, conference proceedings, seminal and contemporary books. 
Table 1

Synopsis of Sources Researched in Literature Review

\begin{tabular}{lcccc}
\hline \multicolumn{1}{c}{ Reference Type } & Total & $\begin{array}{c}\text { \% of total } \\
\text { references }\end{array}$ & $\begin{array}{c}<\text { than } 5 \\
\text { years }\end{array}$ & $>$ than 5 years \\
\hline $\begin{array}{l}\text { Scholarly and peer- reviewed } \\
\text { articles }\end{array}$ & 151 & 92.07 & 142 & 9 \\
Dissertations & 6 & 3.66 & 4 & 2 \\
Seminal Book & 1 & 0.61 & 0 & 1 \\
Conference proceedings & 3 & 1.83 & 3 & 0 \\
Seminar and contemporary books & 3 & 1.83 & 3 & 0 \\
& & & & \\
\hline
\end{tabular}

\section{Literature Search Strategy}

The search terms included: small firms, small and medium enterprises, access to finance, access to credit, firm size, financial constraints, problems facing entrepreneurial firms, strategic planning, social capital, succession planning, qualitative research, case study, group lending, and relational banking.

The literature review for this doctoral study comprised information from authors whose findings are similar and dissimilar as regards the phenomenon. Additionally, the literature review contained factors constraining SMEs' accessibility to credit, and the effect of those factors on the performance of the enterprises. The critical analysis and synthesis of the literature depicted an in-depth understanding of the extent of the problem concerning accessibility to credit by SMEs.

\section{Purpose of the Study}

The purpose of this qualitative multiple case study was to explore what strategies some Kenyan SME business owners used to access credit within the past 5 years to improve company profitability and growth. The target population consisted of four 
Kenyan SME owners of businesses located in Kakamega Town, Kenya, who have had access to credit to improve company profitability and growth. Using face-to-face semistructured interviews with four SME business owners, I achieved data saturation. Additionally, an examination of each business owner's company documents in the form of cash flow and profit and loss statements was supplemental data for analysis. The data from this study might affect social change by contributing to SME business owners accessing credit to ensure sustainable business growth that could potentially enhance community standards of living.

\section{Social Capital Theory}

Hanifan developed the social capital theory in 1916. Although Hanifan used the theory to explain how members of a rural school community accumulated their social capital improve the school performance, several theorists (Bourdieu,1986; Granovetter, 1983; Jonsson \& Lindbergh, 2013; Kontinen \& Ojala, 2012; Nahapiet \& Ghoshal, 1998; Pearson, Carr, \& Shaw, 2008; Putnam, 1995; Tsai \& Ghoshal, 1998; Woolcock \& Narayan, 2000) later extended the theory into business. Specifically, the theorists used the theory to explain how poor people accumulate their social capital to access resources to improve the performance of their businesses. People who network are more likely to accumulate their social capital to achieve more than those who do not. Similarly, Granovetter (1983) stated that through weak ties (acquaintances), network members could access information and resources beyond those available in the social circle (e.g., close friends) to achieve a common goal. Granovetter (1983) concurred with Hanifan's theory that individuals by themselves cannot achieve much unless they worked together to exploit opportunities. Similarly, Bourdieu (1986) termed social capital as the aggregate 
of the actual or potential resources linked to a durable network of relationships, which provides its members with collective access to credit. Both Granovetter (1983) and Bourdieu (1986) tended to agree with Hanifan that individuals could work together to access resources and improve their performance, which would not otherwise be possible. Putnam (1995) explained that strong family bonds and good neighborliness were fundamental to the accumulation of social capital in the community. For example, Putnam found that people who trust one another formed membership associations to participate in politics, education matters, or social entertainment. Today, to acquire a certain job requires one to be a member of certain associations. Through these associations, the leaders strive to secure jobs for their members. Many such associations lease business premises exclusively to their members, a sign that social capital is still an invaluable asset. Putnam agreed with Hanifan's theory in which individuals and families work together as a social unit to access resources to achieve a common goal. Nahapiet and Ghoshal (1998) developed three constructs of the social capital theory to describe how firms facilitate the combination and exchange of resources to achieve a common goal. These constructs of the social capital theory are structural, relational, and cognitive capital. Leaders of firms can combine the three constructs to improve their intellectual capital, innovation, and value creation in ways that would not otherwise be possible. There is a need to share both the tangible and intangible resources of the firm to improve the performance of the business. Leaders of firms need financial resources, knowledge, and capabilities to help achieve their target performance. Although Nahapiet and Ghoshal introduced new constructs, they concurred with Hanifan's theory specifically relevant to 
relations in that individuals can work together to accumulate their social capital to achieve a common purpose.

Woolcock and Narayan (2000) used the social capital theory to describe how poor entrepreneurs in developing countries formed networks to access information and financial resources to improve business performance. Woolcock and Narayan revealed how poor communities use social capital to access resources and protect themselves against risks and uncertainties. Poor borrowers without adequate collateral in developing countries can use social capital to access credit from formal financial institutions. In fact, Mwangi and Ouma (2012) revealed that poor borrowers who have no collateral assets and are without a credit history use social capital to access credit to sustain their businesses. Ong'indo (2014) found that social capital allows individuals to establish relationships based on norms and trust to reduce transaction costs and thereby gain access to credit. Pearson, Carr, and Shaw (2008) used the three social capital dimensions, structural, relational, and cognitive, to identify the unique behavioral resources and capabilities of family firms. Family firm owners can make use of the knowledge, skills, and social capabilities of their members to access information and resources with which to improve business performance. Pearson et al.'s (2008) idea of the use of social capital to facilitate the exchange of resources between firms aligns with Hanifan's theory in which individuals and families work together to achieve a common purpose. Kontinen and Ojala (2012) described how family firm owners use social capital to access resources to enhance their international operations. Kontinen and Ojala revealed that the lack of external social capital prevented family firms from adapting to environmental changes. Family firm owners need to improve their external social networks to access resources 
and facilitate innovation and internationalization programs (Kontinen \& Ojala, 2012). To venture into an international business requires the establishment of strong personal relationships to access information and resources in the host country. For example, international firm owners can connect with those in the foreign country to help understand the local business environment. Prasad, Tata, and Guo (2012) found that small business owners in the United States use social capital to access credit during times of recession to sustain themselves. Small business owners need to collaborate to access financial resources to achieve long-term sustainable performance (Prasad et al., 2012). Jonsson and Lindbergh (2013) explained how entrepreneurs use social capital to obtain external funding during the firm's development stage when internal sources of finance are insufficient. Jonsson and Lindbergh used the three dimensions of social capital, structural, relational, and cognitive, to demonstrate how firms exchange resources to sustain their businesses. Firms that are at the initial formative stages and without collateral can use their social capital to establish external networks to access credit for their businesses. Stephens (2013) stated that entrepreneurs of new ventures use social capital to access information and other resources to improve the performance of their businesses. For example, Bridge (2013) established that firms often use social capital to establish social connections to obtain resources that would otherwise be costly to acquire. Individuals who interact and communicate with one another are more likely to develop strong personal relationships to facilitate exchange of resources than those who do not. Bhatt and Altinay (2013) described how social entrepreneurial ventures (SEV) in India used social capital to overcome resource constraints. Firm owners can build trust and cooperation among their members to help establish personal relationships with external 
investors to access financial resources for their businesses. Adama and Nadif (2013) found that firms use social capital to access information and financial resources to ensure the survival of the company. Managers can use their goodwill, trust, and cooperation among members to establish networks with other firms and thereby gaining access to financial resources for their businesses.

Despite the support for the social capital theory, several authors have leveled criticism against Hanifan's theory (Adama \& Nadif, 2013; Adler \& Kwon, 2002; Carlos \& Pinho, 2013; Kontinen \& Ojala, 2012; Light \& Dana, 2013; Schulman \& Anderson, 1999; Woolcock \& Narayan, 2000), stating that social capital is uneven among groups, making it difficult for some firms to access resources to sustain their businesses. For example, Light and Dana (2013) found that powerful groups exploit resource monopolies to lock less powerful groups out of business. Dominant groups within a network may use their powers to influence accessibility to resources, causing the subordinate groups to quit the business because of lack of funds. Woolcock and Narayan (2000) revealed that despite 200,000 community groups in rural Kenya, social capital could not help them to access external resources or reduce poverty. Firm owners may form social networks to access resources for their businesses, but without proper use of these resources, social capital is meaningless. Adler and Kwon (2002) discovered that building social capital requires considerable investment regarding establishing and maintaining relationships. For example, establishing external networks takes more time, money, and effort than depending on those within the social circle (e.g., close friends). Having limited social capital hinders firm owners from gaining access to credit, which affects long-term sustainable relationships (Kontinen \& Ojala, 2012). The inability to gain access to 
financial resources affects the performance of the business, which makes the social capital theory meaningless. Carlos and Pinho (2013) stated that lack of trust among members of a network increases vulnerability, which affects social relations. Trust and cooperation among members are fundamental to the success of a network to facilitate access to information and financial resources to support the business. When people do not trust each other, it becomes difficult to work together to achieve a common goal.

Despite the limitations, the social capital theory is still applicable to small business owners especially those that have no physical collateral to facilitate accessibility credit. For example, Mwangi and Ouma (2012) found that poor borrowers who have no physical collateral, and with no credit history, use social capital to access credit to support their businesses. Hassan (2014) concurred with Mwangi and Ouma that poor borrowers with no collateral assets used their social networks to cooperate and access resources to achieve a common purpose.

This social capital theory applied to this research study because the three constructs (a) structural capital, (b) relational capital, and (c) cognitive capital helped to explore what strategies some Kenya SME business owners use to access credit to improve company profitability and growth. Nahapiet and Ghoshal (1998) developed the three constructs of the social capital theory to describe how firms facilitate the combination and exchange of resources to improve the performance of their businesses. The following are the constructs underlying the social capital theory.

\section{Structural Capital Construct}

The structural capital dimension comprises network ties among members of a group. Whom you reach, how you reach them, and when to reach them determines the 
direction of the business. Walker, Kogut, and Shan (1997) described how existing firms or start-ups establish networks to exploit new business opportunities. Today to find a job or buy property, one needs to have a strong social connection. Pearson et al. (2008) used the structural dimension of capital to describe how families develop internal network ties to create the potential for social capital appropriate to the family firm. Gao, Sung, and Zhang (2013) stated that network ties facilitate social interactions and channels for knowledge exchange among members of a group. Entrepreneurial firm owners can use the trust and goodwill of its members to establish external networks to access resources for their businesses. People, who trust one another and work together are more likely to share knowledge and experiences on how to solve problems than those who do not. Kontinen and Ojala (2012) stated that strong social relations among members of a network allow the manager to access information and financial resources to exploit new business opportunities.

Simen (2013) established how Chinese foreign firms use social capital to establish collaborative networking to facilitate international business operations. For example, Chinese business owners use kinship network to establish contacts with the local businesspeople in the host country to create a favorable business environment, which facilitates international operations. Networks promote trust and cooperation among their members by providing sanctions against those who deviate from the norms of the group. Nahapiet and Ghoshal (1998) explained that firms within a network could use referrals to access information and facilitate the exchange of knowledge to improve the performance of their businesses. Today one needs a referral to get a good job or buy a prime parcel of land, a sign that social capital is still applicable. 
Despite the benefits, social networks contain certain limitations. Chazdon, Allen, Horntvedt, and Scheffert (2013) stated that members of weak bridging networks tend to experience conflict among separate insider groups vying for control of decision-making. Networks comprise individuals who have more or limited powers, making it difficult to function smoothly. For example, lack of trust and cooperation among group members may result in internal conflicts, which affect the performance of the network.

\section{Relational Capital Construct}

The relational construct of social capital theory comprises the norms, values, and obligations of members within a network (Nahapiet \& Ghoshal (1998). This construct contains an emphasis on the behavioral aspects of an individual including respect and friendship. People who trust and respect each other tend to work together to meet the obligations of others within the network. Nahapiet and Ghoshal stated that norms of cooperation allowed members of a network to create a strong foundation to facilitate the exchange of intellectual capital to access resources for the business. Pearson et al.(2008) found that personal bonds facilitate cooperation and communication to achieve a common goal. Lu, Feng, Trienekens, and Omta (2013) used the relational dimension of social capital to describe how strong guanxi (relationships) network and interpersonal trust significantly contribute to high performance in Chinese firms.

Despite the significance, the relational construct of social capital theory has some limitation. Lack of trust among the members of a network may result in poor personal relationships, which affects cooperation and communication. SME business owners need to develop strong personal relationships to facilitate communication and cooperation among members of a network to access financial resources for their businesses. 


\section{Cognitive Capital Construct}

Nahapiet and Goshal (1998) discovered that people with shared vision, language, cultural values, stories, and systems often tend to work together for a common purpose. Jonsson and Lindbergh (2013) used the cognitive dimension of social capital to describe how members of a network share language and systems of meaning to access information and resources, which they could not otherwise obtain. Individuals with a shared vision and language often trust each other, which facilitates the exchange of knowledge to access resources to sustain their businesses. Pearson, Carr, and Shaw (2008) used the cognitive dimension of social capital to describe how the family and the firm merge to create collective understanding and cooperation to achieve long-term goals. When people have a shared vision, nothing will stop them from working together to achieve a common purpose. However, the cognitive dimension of social capital has its limitation. Lack of new knowledge affects motivation, resulting in many members leaving the network. SME business owners need to share knowledge, values, and systems to create a collective understanding and collaboration to facilitate access to information and financial resources to achieve long-term sustainable performance.

The structural capital, relational capital, and cognitive capital dimensions of the SCT may help Kenya SME business owners develop effective strategies to obtain credit. There is a need for small businesses to invest in the three social capital dimensions to protect themselves from uncertainty and mitigate resource constraints (Prasad et al., 2012). Kansikas, Laakonen, Sarpo and Kontinen (2013) used the structural, relational, and cognitive capital dimension of social capital to group the resources available to the family firm. Several studies (Adama \& Nadif, 2013; Bhatt \& Altinay, 2013; Bourdieu, 
1986; Mwangi \& Ouma, 2012; Stam, Arzlanian, \& Elfring, 2013) revealed that small businesses use social capital to gain access to information and financial resources to sustain their businesses. Bourdieu (1986) agreed that well- connected actors use social capital to access intellectual and financial resources to improve the performance of their businesses. Mwangi and Ouma (2012) established that social capital allows small businesses to obtain credit information to facilitate collective decision-making and access financial resources. Adama and Nadif (2013) stated that social capital allows SME business owners to access information to exploit new business opportunities and ensure sustainable competition.

The social capital theory contains the constructs that small businesses can apply to develop strategies to overcome resource constraints by mobilizing other forms of capital and facilitating trust and cooperation (Bhatt \& Altinay, 2013). Stam et al. (2013) discovered that firms use social capital to obtain resources to exploit new business opportunities and achieve long-term sustainable performance.

Hanifan (1916) explained how social capital theory contains the constructs that, if applied, may allow people with limited resources to work together to achieve a common purpose. For this study, I used the social capital theory as the lens to obtain an in-depth understanding of what strategies some Kenyan SME business owners use to access credit to improve company profitability and growth.

\section{Critical Analysis, Synthesis, and Compare and Contrast of Themes}

Eleven themes emerged during the literature research process, and each relates to this qualitative case study. The research topics include small and medium enterprises' accessibility to credit, entrepreneurial education and training, the effect of access to 
credit on SME performance, firm characteristics, government support, group lending, information availability, multiple bank relationships, strategic planning, succession planning, and venture capital.

\section{Small and Medium Enterprises' Accessibility to Credit}

Small and medium enterprise (SME) business owners play a significant role in the Kenyan economy. These business owners contribute to job creation, income generation, and poverty alleviation (Hassan, 2014; Njeru, 2012; Osoro \& Muturi, 2014). For developing countries, the United Nations Industrial Development Organization (UNIDO) defined small and medium enterprises as those employing between one and 99 workers (Narteh, 2012). The research studies include the constraints facing Kenya SME business owners and managers in accessing credit over the past decade. Despite their significance, Kenya SMEs face financial challenges that affect their profitability and growth. Several studies (Gaitho, 2013; Gichuki, Njeru, \& Ondabu, 2014; Makena, Kubaison, \& Njati, 2014; Moyi, 2012; Mwobobia, 2012 Onyango \& Achieng, 2013) revealed a lack of collateral as a constraint to gaining access to credit. Although these researcher findings were similar, they had other varying findings. In addition to the lack of collateral, Gichuki et al. (2014) found high processing fees and short repayment period constrained SMEs' access to credit. Makena et al. (2014) found cultural norms as a barrier to accessing credit as a unique finding. Like majority African cultures, the Kenyan culture does not allow women to own property, which constrains their access to credit. Additionally, Makena et al. (2014) revealed that poor access to information was a constraint to SMEs' access to credit. Gaitho (2013) found that lack of credit information caused banks to factor in a risk premium in the pricing of credit, which contributed to the 
high cost of borrowing. Additionally, Gaitho (2013) revealed that having a credit reference bureau (CRB) allows banks to share credit information on prospective borrowers, which facilitates the assessment of credit requests. Sharing of credit information allows the banks to mitigate the risks of bad debts to reduce the cost of credit and thereby enhancing access to credit. Moyi (2013) found that limited access to technology and permanent work sites were a constraint on SMEs' access to credit. Strategically located firms that have access to technology were more likely to access information than those that are not, thereby gaining access to credit. Nkonge (2013) also revealed that rigid financial regulations were a constraint to gaining access to credit. No other studies indicated this finding. Extending the list of constraints to gaining access to credit, Onyango and Achieng (2013) discovered that poor business planning, poor management, and insufficient credit history of the borrower affects SMEs' access to credit. Mwobobia (2012) found similar results that lack of planning and poor management were constraints to gaining access to credit. Majority SMEs have no clear business plan on how to sustain their profitability, which hinders their access to credit. Nkonge (2013) studied the challenges facing SME business owners bidding for tenders in Kenya. Nkonge revealed that rigid financial regulations, shortage of financial resources and poor access to information constrained SMEs from participating in the tendering process.

Similarly, studies in other developing countries also indicate that SME business owners have difficulties in accessing credit to sustain their businesses. Atogenzoya, Nyeadi, and Atiga (2014) studied the use of land as a collateral requirement by financial institutions when lending to SMEs in Ghana. Atogenzoya et al. (2014) found that lack of 
collateral and high loan transaction costs were a major constraint to accessing credit. Kira (2013) found similar findings when they conducted a study to evaluate the financial constraints facing five East African countries: Burundi, Kenya, Rwanda, Tanzania, and Uganda. Kira revealed that poor access to information and high loan transaction costs was a barrier to accessing credit in all the five countries, forcing some SMEs to use internal sources to finance their businesses. Based on these findings, SMEs in developing countries face significant challenges in accessing credit to sustain the profitability and growth of their businesses.

\section{Entrepreneurial Education and Training}

The education, training and knowledge of the entrepreneur are important to the financial success of any business. Jonsson and Lindbergh (2012) found that social capital allows individuals to share a language, vision, values and learning processes to facilitate the exchange of information and knowledge creation. Entrepreneurs who have higher formal education and training are more likely to share knowledge to facilitate access to information than those who do not have, and thereby gaining access to credit. Several studies (Hassan \& Mugambi, 2013; Mbugua, Mbugua, Wangoi, Obada, \& Kariuki, 2013; Ongachi \& Bwisa, 2013; Ong'injo, 2014 Waithaka, Marangu \& Ng'ondu, 2014) revealed lack of formal education and training among SME business owners was a major constraint to gaining access to credit. Although these researcher findings were similar, they had varying results. Ong'injo (2014) found that low literacy levels and general ignorance were constraints to gaining access to credit. Waithaka, Marangu and Ng'ondu (2014) also discovered that lack of seminars and workshops for SME business owners was a barrier to accessing credit. Waithaka et al., 2014) revealed that lack of information 
on where to obtain professional and financial services was a major constraint to SMEs' gaining access to credit and other resources to sustain their businesses. Entrepreneurs who have a higher formal education and managerial training were more likely to access information than those who do not have, and thereby gaining access to credit and other resources to improve the performance of their businesses.

Similarly, several studies (Agyei-Mensah, 2013 Bridge, 2013 Omari, Nazri, \& Wel, 2014 Sandhu, Hussain, \& Matlay, 2012) in other countries also revealed a lack of education and training among entrepreneurs as major constraints to gaining access to credit. Although these studies researcher findings were similar, they had other varying findings. In addition to the lack of education and training, Bridge (2013) found that social capital has not helped SMEs to access entrepreneurial education. No other studies revealed this finding. Bridge discovered that lack of social capital limits access to information and thereby constraining access to credit. In summary, the studies indicate that entrepreneurs who have higher formal education and training were more likely to access information than those who do not have, and thereby gaining access to credit and other resources to sustain the performance of their businesses.

Conversely, Nguyen, and Luu (2013) found that SME business owners who have a higher formal education and training were more likely to know the lending requirements than those who do not have, and thereby refraining from applying for credit. Nguyen and Lu (2013) revealed that entrepreneurs who have better education and training finance themselves through internal sources, which reduces the demand for credit. Despite the different schools of thought, majority studies indicate that lack of 
education and training of entrepreneurs was a major constraint to accessing credit because of lack of information.

\section{Effect of Access to Credit on SME Performance}

Empirical evidence indicates that there is a positive correlation between access to credit and performance of small businesses. Several studies (Bunyasi, Bwisa, \& Namusonge, 2014; Kisaka \& Mwewa, 2014; Njeru, 2012 Osoro \& Muturi, 2014) revealed that there was a positive correlation between access to credit and the performance of SMEs. Although these researcher findings were similar, they had other varying findings. In addition to the positive effect of credit on the performance of SMEs, Kisaka and Mwewa (2014) found that inappropriate training among SME business owners was a major constraint to accessing credit information, and thereby constraining access to credit. Kisaka and Mwewa (2014) revealed that formal financial institutions perceived SMEs as high risk and commercially unviable because of their poor and insufficient capacity to deliver financial services, which hinders access to credit to improve business performance.

Conversely, several studies indicate that there is no positive correlation between access to credit and the performance of SMEs. Agwu and Emeti (2014) found that lack of managerial skills and multiple taxations have a positive effect on the performance of SMEs and not access to credit. A business may have access to credit but without good management, there will be no business performance. Mwobobia (2012) agreed that other factors such as discrimination, multiple roles, and lack of education affect the performance of SMEs. Additionally, Mwobobia (2012) revealed that many potential clients perceive small businesses as lacking the ability to provide quality services, which 
affects their performance. Despite the effect of other factors, the inability to access to credit is a major constraint on the performance of SMEs. SMEs that have access to credit were more likely to improve their performance than those that do not have.

\section{Firm Characteristics}

Several studies (Musamali \& Tarus, 2013 Mendes, Serraqueiro, \& Nunes, 2014; Nguyen \& Luu, 2013; Wachilonga, 2013; Yildirim, Akci, \& Eksi, 2013) revealed that there is a positive correlation between firm characteristics and the choice of credit financing for SMEs. Musamali and Tarus (2013) defined firm characteristics to include ownership structure, the size of the firm, business type, and age of the business. Musamali and Tarus (2013) found that large firms were more likely to access credit than small firms because of their strong asset base. Nguyen and Luu (2013) agreed that large firms access alternative funding compared to small firms because of their strong asset base. In addition to strong asset base, Nguyen and Luu established that young firms lack quality information, which constrains access to credit. Mendes, Serraqueiro, \& Nunes, (2014) found similar results when they conducted a study to examine the investment determinants of young and old Portuguese SMEs. Mendes et al. (2014) revealed that young firms with low levels of investments have difficulties in accessing credit than old ones. Young firms often lack the credit history required by financiers as a condition for lending. Wachilonga (2013) studied how firm size and financial source preferences of the hotel and lodging business influence the capital structure of SMEs. Wachilonga (2013) found that owners of hotels and lodges preferred to use internal sources of financing because of lack of assets as collateral for obtaining a bank loan. Yildirim, Akci, \& Eksi (2013) found that sales volume and stability of the firm influence SMEs' access to credit. 
No other researcher findings indicated this finding. Firms that have large sales volume were more likely to make higher profits than those that do not have, and thereby gaining access to credit.

Conversely, Njeru, Namusonge, and Kihoro (2012) stated that there is no significant relationship between firm characteristics and SMEs' access to credit. Njeru et al. (2012) explained that not all financiers consider firm size as a determinant factor when lending to SMEs. Despite the contrary findings, firm characteristics such as ownership structure, the size the firm, and location of business play an important role in determining SMEs' access to credit. Firms that are strategically located and incorporated were more likely to access credit than those that are not.

\section{Government Support}

The availability of government support is important to the performance of small and medium enterprises (SMEs). Several studies (Cant, Erdis \& Sephaso, 2014; Ekpe, Razak \& Mat, 2013 Ndagjijima\& Oketch, 2014; Ooi \& Ahmad, 2012 Rambo, 2012 Xiang \& Worthington, 2013). Cant et al. (2014) revealed that firms that do not receive government support were more likely to depend on bank loans to finance their businesses

than those that do. In addition to the lack of government support, Ekpe et al. (2013) found that gender discrimination was a constraint to gaining access to credit. Ekpe et al. agreed with Mwobobia (2012) that gender discrimination was a barrier to accessing credit, specifically for women entrepreneurs. Ndagjijima and Oketch (2014), Ooi and Ahmad (2012), and Rambo (2012) found that rigid legal and regulatory framework was a constraint to gaining access to credit. Specifically, Ndagjijima and Oketch, and Rambo established that majority SMEs that rely on bank credit pay high- interest rates because of 
high transaction costs and long processing time. Additionally, Rambo revealed that high cost of energy and high taxes affected the profitability of SMEs, which constrains access to credit.

Ooi and Ahmad (2012) found that undergraduate students were unable to launch a venture because of legal and regulatory constraints. Ooi and Ahmad (2012) revealed that high transaction costs were a major constraint to gaining to access to credit for the undergraduate students who want to start a new venture. Xiang and Worthington (2013) studied the effectiveness of government financial support provided to SMEs during the recent global financial crisis (GFC). Xiang and Worthington (2013) found that firms that receive government financial assistance were more likely to obtain credit in the following year because of implied guarantee than those that do not receive. The government needs to assist financially constrained SMEs to access credit to sustain their businesses. However, I did not find any study that has contrary findings regarding government support for SMEs.

\section{Group Lending}

Small and medium enterprises (SMEs) that have no adequate collateral can use group-lending strategy to gain access to credit for their businesses. Nahapiet and Ghoshal (1998) found that social capital allows members of a network to develop strong personal relationships that provide the basis for trust and cooperation to achieve a common purpose. Social capital allows people who have no tangible assets as collateral to form organized groups to reduce uncertainty and gain access to credit to sustain their businesses. Several studies (Kiragu \& Sakwa, 2013; Mwangi \& Ouma, 2013; Naveen, 
2012; Nawai \& Shariff, 2013 Wanambisi \& Bwisa, 2013) revealed that organized groups allow SMEs to gain access to credit because of joint liability.

Kiragu and Sakwa (2013), Naveen (2012), and Nawai and Shariff (2013) found that joint liability allows group members to screen, monitor and enforce each other's loan habits. Group monitoring helps improve loan repayment, which facilitates further credit. Additionally, Kiragu and Sakwa (2013) explained that group lending mechanisms allow entrepreneurs to acquire administrative and supervisory skills thereby facilitating access to credit. Mwangi and Ouma (2012) established that majority SMEs were unable to access credit because of poor access to information, forcing financiers to ask for guarantors. Groups allow members to share information and guarantee one another, which facilitates access to credit and repayment of loans. In addition, to the joint liability, Wanambisi, and Bwisa (2013) revealed that SME business owners should join groups to enhance access to credit for their businesses.

Conversely, Dube (2012) studied the experiences and perceptions of Swaziland Women's Finance Trust regarding group lending. Dube found that large sizes of groups, insufficient information, and poor design and implementation affected group lending. Dube (2012) revealed that high presence of family members within the group and poor management affected repayment of loans, which constrains access to further credit. Despite the contrary, groups remain an effective strategy for SMEs that have inadequate collateral to access credit for their businesses. SMEs that have group strategies are more likely to access credit and manage loan repayment because of a joint liability than those that do not have. 


\section{Information Access}

The availability of information is important for the choice of credit financing for business. SMEs that have higher quality information are more likely to access credit than those that do not have. Several studies (Akomea \& Sampong, 2012; Bunyasi et al., 2014; Devinaga \&Tan, 2012; Njeru, Nyangaresi, \& Waithaka, 2013; Standa, 2013; Yesseleva, 2013) revealed that majority SMEs have difficulties accessing credit because of poor access to information. Akomea-Bonsu and Sampong (2013) hypothesized that there was a relationship between the implementation of information communication technology (ICT) and the increase in productivity of small and medium enterprises in Ghana. Akomea-Bonsu and Sampong (2012) found that majority firms use the Internet to locate customers and general business information rather than seeking financial resources. Akomea-Bonsu and Sampong (2012) revealed that lack of internal capabilities was a constraint to adopting information communication technology (ICT) to access information, which constrains access to credit. In addition to poor access to information, Devina and Tan (2012) found that the government provided information related to financing, advisory services, and training to help SMEs gain access to credit. No other studies indicated this finding. Njeru et al. (2012) also revealed that access to information allows SMEs to access credit to exploit business opportunities and achieve long-term sustainable growth. Standa (2013) found that lack of communication strategies among entrepreneurs was a constraint to accessing information, which hinders access to credit. No other studies indicated a lack of communication strategies. Yesseleva (2013) found unique results when he conducted a study to examine the effect of professional advice on SMEs' access to credit. Yesseleva (2013) revealed that entrepreneurs who receive 
professional advice from accountants and financial experts were more likely to access credit than those who do not. SME business owners need to improve their communication strategies to help access information and obtain credit to sustain their businesses.

However, I did not find any contrary study finding concerning the effect of information availability on SMEs' accessibility to credit. There is a need for SMEs to improve the quality of their information to facilitate access to credit and other resources.

\section{Multiple Bank Relationships}

Developing close bank relationships is important to the funding decisions of small and medium enterprises (SMEs). Kang, Zardkoohi, Paetzold, and Frazer (2013) found that social networks encourage embeddedness among economic factors to pursue relationships characterized by trust and reciprocity to access information and financial resources to sustain the business. Several studies (Berger, Goulding, \& Rice, 2014; Gambini \& Zazzaro, 2013; Maenpaa, 2012; Narteh, 2012; Shikimi, 2013 Wambua \& Mugambi, 2013) revealed that developing multiple banking relationships allows SMEs to gain access to credit to improve their businesses. Although these researcher findings were similar, they had other varying results. In addition to gaining access to credit, Berger, Goulding, and Rice (2014) found that SMEs develop multiple banking relationships to avoid premature withdrawal of services in case the main bank fails to deliver. Wambua and Mugambi (2013) agreed that SMEs develop multiple banking relationships to help access services in case the main bank is distressed or fails to deliver. Additionally, Berger et al. (2014) revealed SMEs that have poor access to information depend on several banks including the main bank to gain access to credit and other financial resources. Gambini and Zazzaro (2013) found similar results when they conducted a study to 
examine the effect of banking relationship on the growth of SMEs. Gambini and Zazzaro (2013) revealed that SMEs that have poor access to information developed multiple banking relationships to gain access to credit. Additionally, Gambini and Zazzaro (2013) revealed SMEs that develop multiple banking relationships are more likely to grow faster than those that do not.

In addition to access to credit, Narteh (2013) established that SMEs develop multiple banking relationships to facilitate cash collection, transfers, bank guarantees, and advisory services. No other studies indicated this finding. Narteh (2013) revealed that older SMEs use multiple banking relationships to gain access to credit than new ventures because of availability of information. Shikimi (2013) found unique results when she conducted a study to examine the effect of multiple banking relationships on the cost and availability of credit to SMEs. Shikimi (2013) revealed that multiple banking relationships allow SMEs to gain access to credit despite the high transaction costs.

Conversely, Maenpaa (2012) found that SME business owners operate multiple banks to help meet the changing needs of their customers, and not gain access to credit. Despite the different schools of thought, SMEs need to develop strong multiple banking relationships to enhance access to credit and other financial resources to improve the performance of their businesses.

\section{Strategic Planning}

Effective strategic planning is fundamental to the success of the business. A Strategic plan provides a road- map that leads an organization from where it is now to where it would like to be in the future (Kariuki, 2015). A well-developed strategic plan allows the business to implement its policies and monitor the operations to achieve the 
desired performance. Ahmed and Muntaka (2012) discovered that CEOs with internal loci of control outcomes, implement the structures and processes of environmental monitoring to meet the contingencies of their chosen strategies. SME business owners that have a clear vision and business plan are more likely to gain access to credit and other resources than those that do not have. Several studies (Awino, 2013, Jaoua \& Radouche, 2014; Kagwathi, Kamau, Njau, \& Kamau, 2014; 2014; Kariuki, 2015; Mitchelmore \& Rowley, 2013 Napoli, 2012 Njoroge \& Wario, 2015 Sandada, Pooe, \& Dhurup, 2014) revealed that lack of strategic planning was a constraint to SMEs' gaining access to credit to improve the performance of their businesses.

Awino (2013) found SMEs that use strategic planning were more likely to gain access to credit and other financial resources than those that do not, which results in sustainable business performance. Jaoua and Radouche (2014) agreed that strategic planning allows companies to access credit to improve the performance of their businesses. Kagwathi et al. (2014) found SMEs lack risk mitigation strategies, which affects their credit scorecards. Kagwathi et al. revealed that a credit score allows SMEs to access formal credit that matches the risk and performance of the business. Firms that have strategic planning are more likely to mitigate risks and increase their credit score than those that do not have, and thereby gaining access to credit. Kariuki (2015) found that SMEs have no clear vision of what they desire to accomplish and how which limits their access to credit. Majority SMEs lack a clear business plan on what to do and how to do it to achieve profitability as a requirement for accessing credit. Napoli (2012) studied the effects of corporate processes of strategic change in the performance of family-owned SMEs. Napoli found that the strategic leadership of SMEs often lies in the hands of a 
single individual, which affects decision-making on how to pursue financial resources to sustain the business. Napoli revealed that individuals who do not belong to the dominant family had a positive influence on the strategic change of the business. Njoroge and Wario (2013) agreed that individual values and lack of strategic planning were a constraint to accessing credit among SMEs. Family-owned firms need to develop a strategy of hiring a non-family member to help attract external financial resources to sustain their businesses. Mithelmore and Rowley (2013) found that strategic planning allows SMEs to set goals and allocate resources to realize these goals. Mitchelmore and Rowley revealed SMEs that neglect strategic planning is more likely not to achieve their potential performance and growth than those that do not. Sandada, Pooe, and Dhurup (2014) found similar results in his study to determine the relationship between strategic planning and performance of SMEs. Sandada et al. revealed that SMEs that have strategic planning were more likely to attract financial resources than those that do not have. Strategic planning allows SMEs to make decisions on how to improve the profitability of their businesses to help access credit and other resources.

Overall, I did not find any contrary researcher findings concerning the role of strategic planning as relates to SMEs' access to credit. SME business owners need to have strategic planning to determine where they are and where they would like to be in the future. A good strategic plan provides the financiers with the assurance that the business is committed to making profits to repay their money.

\section{Succession Planning}

Business succession is one of the greatest management challenges facing familyowned SMEs. Boyd and Royer (2012) discovered that family firms worldwide are facing 
succession business challenges that limit their access to credit. Several studies (Chaimahawong \& Sakulsriprasert, 2013; Karanja, 2012; Koropp, Gricnik, \& Gygax, 2013; Nordqvist, Wenberg, Bau, \& Hellerstedt, 2013) found that proper succession planning and post- succession planning allows SMEs to access credit because of continuity of business. Chaimahawong and Sakulsriprasert (2013) found SMEs that have a business succession plan could gain access to credit because of their continuity of business. Nordqvist, Wenberg, Bau, and Hellerstedt (2013) established that SMEs tend to ignore ownership transition, which affects access to credit because of uncertainty about the continuity of their businesses. A good business succession plan provides the financiers with the assurance that the business will be able to meet their obligations after the exit of the owner. Karanja (2012) studied how succession planning affects the survival of small and medium family enterprises (SMFEs ) in Kenya. Karanja (2012) found SMFEs that have a clear succession plan were more likely to access credit and other financial resources than those that do not have. Koropp, Gricnik, and Gygax (2013) revealed that a good succession plan allows a firm to determine its debt usage intentions and ensure further access to credit after the exit of the business owner. Chung and Luo (2013) found that social ties and network resources were not only available to outside successors but also inside successors because of their exclusive nature of family ties. No other studies revealed this finding. Chung and Luo revealed that a good business succession plan allows family SMEs to access external network resources to ensure the survival of their businesses.

However, there were no contrary researcher findings on the role of succession planning concerning SMEs' access to credit. SMEs need to develop clear succession and 
post- succession plans to ensure continuity of their businesses and access to credit after the exit of the business owners.

\section{Venture Capital}

Lack of adequate collateral to access bank loan may force SMEs to seek funding from other sources such as venture capital firms to sustain their businesses. SMEs that have no collateral can use their social capital to access credit from non-financial institutions such as venture capital firms. Bouzahir and Chakir (2013) discovered that social capital has an indirect positive effect on higher investment decisions facing more risks, typically venture capitalist investments. Bouzahir and Chakir revealed that social capital allows new ventures to access credit directly or through third parties to sustain the growth of their businesses. Memba, Gakure and Karanja (2012) found similar findings when they conducted a study to examine the impact of venture capital on the growth of small and medium enterprises (SMEs). Memba et al. revealed that venture capitalists not only assist in the provision of funds but also contribute their management skills to improve the performance of SMEs (Quaye \& Sarbah, 2014).

However, several studies ( Guo \& Jiang, 2013; Jagongo, 2012; Quaye \& Sarbah, 2014) revealed that majority SMEs have difficulties in accessing venture capital as an alternative source of funding for their businesses. Jagongo (2012) studied the effect of venture capital financing on the performance of small and medium enterprises (SMEs). Jagongo found that SMEs have no information about venture capital as an alternative source of funding their businesses. In addition to the lack of information, Jagongo revealed that venture capitalists are unwilling to finance SMEs because of their volatility and lack of strategic partnerships. Similarly, Quaye and Sarbah (2014) found that poor 
access to information and lack of financial literacy was a constraint to SMEs' access to funding from non-financial institutions such as venture capital firms.

Conversely, Guo and Jiang (2013) found that venture capitalists invest in projects with growth potential, which locks out majority SMEs from accessing credit to finance their businesses. SMEs need to improve their social capital to help access alternative sources of funding their businesses.

The purpose of this qualitative multiple case study was to explore what strategies some Kenya SME business owners used to access credit to improve company profitability and growth within the past 5 years in Kakamega Town, Kenya. The review of the professional and academic literature contained scholarly articles, seminar, and contemporary books. The literature review summarizes, compares, and contrasts all the sources that relate to my research topic. Based on the research and review of the literature, the strategies of SME business owners to access credit may contribute to sustainable business growth to enhance community standards of living.

\section{Transition}

Section 1 contains the problem statement and purpose statement, as well as the nature of the study that justified using a qualitative method and exploratory multiple case study design. Section 1 also includes the (a) interview questions (Appendix B), (b) conceptual framework, (c) assumptions, (d) limitations, and (e) delimitations of the study. Section 1 contains the conclusion and the significance of the study and a review of the professional and academic literature. The literature review includes extant literature relating to the following sections and subsections (a) social capital theory, (b) small and medium enterprises (SME) accessibility to credit, (c) effect of credit on performance of 
SMEs, and (d) SMEs' strategies to access credit to improve company profitability and growth of their businesses.

Section 2 comprises (a) the restated purpose statement, (b) the role of the researcher, (c) the selected participants, (d) a detailed description of the research methodology and design, (e) the population and sampling, (f) ethical research, (g) data collection instruments and technique, (h) data organization technique, (i) data analysis, and (j) reliability and validity.

Section 3 begins with an introduction including the purpose statement, research question, and findings. Section 3 also contains the application to professional practice, implications for social change, recommendations for action and further study, and a conclusion of the researcher reflections. 


\section{Section 2: The Project}

This section provides an explanation of the approach of the study and the rationale for using the selected methodology. The research methodology and design are a qualitative multiple case study approach. Additionally, Section 2 includes a restated purpose statement, role of the researcher, participants, population and sampling, and ethical research. Furthermore, Section 2 contains data collection, data analysis techniques, and reliability and validity. The purpose of this study was to explore and present an in-depth understanding of the strategies some Kenya SME business owners used to access credit to sustain their businesses within the past 5 years. I interviewed four owners of SME businesses in Kakamega Town, Kenya, to obtain in-depth information about the phenomenon using a qualitative multiple case study approach.

\section{Purpose Statement}

The purpose of this qualitative multiple case study was to explore what strategies some Kenya SME business owners used to access credit to improve company profitability and growth within the past 5 years. The target population consisted of four Kenya SME owners of businesses located in Kakamega Town, Kenya, who have had access to credit to improve company profitability and growth. Face-to-face semistructured interviews with four SME business owners ensured data saturation. Additionally, an examination of each business owner's company documents in the form of cash flow and profit and loss statements was supplemental data for analysis. The data from this study might affect social change by contributing to SME business owners accessing credit to ensure sustainable business growth that could potentially enhance community standards of living. 


\section{Role of the Researcher}

In this qualitative multiple case study design, I was the data collection instrument. My role as the researcher of the study was to select the appropriate research methodology and design, recruit potential participants, and analyze the data. The study commenced with an extant review of the literature to obtain an in-depth understanding of the research study topic. Peredaryenko and Krauss (2013) argued that researchers construct and bring meaning into the world through the qualities of sensitivity, responsiveness, and flexibility, making them the most appropriate research instrument for inquiries. From the literature review, I used data for the study to address the research question. The research question for this study was: What strategies do some Kenyan SME business owners use to access credit to improve company profitability and growth? I made telephone calls to the four Kenya SME business owners to present the research topic and ask for their participation. I had never been an SME business owner, and I have never worked for an SME business in Kakamega Town. I knew SME business owners and entrepreneurs in the area because I had lived in Kakamega Town. I used to shop at these businesses in Kakamega Town, so this topic was of particular interest to me. I have always had a passion for and interest in the SME businesses in the community. I used a few long-term friends who stay in Kakamega Town to help access the potential participants after receiving the IRB approval. Whiteley (2012) described a researcher is an instrument of data collection who gives voice to the participants and preserves their authentic responses. A qualitative researcher should collect data as well as protect the participants to ensure a credible research process. Whiteley emphasized that qualitative researchers need to protect human subjects to ensure a smooth research process. 
The Belmont Report (1979) contains a summarization of the ethical principles and guidelines for research involving human subjects. The National Commission for the Protection of Human Subjects of Biomedical and Behavioral Research Subjects initially wrote the report. The Belmont Report includes a distinction between research and practice, the three basic ethical principles, and the application of these principles. In this study, I used the three basic ethics of research involving human subjects to ensure a smooth research process. To achieve this, I treated the participants with respect and dignity to build trust to ensure a proper researcher-participant working relationship. These principles include (a) respect of persons, (b) beneficence, and (c) justice. The principle of respect for persons requires researchers to treat individuals as autonomous agents. Human subjects should enter into the research voluntarily and with adequate information (Belmont Report, 1979).

Qualitative researchers strive to bracket out their views to deepen their understanding of the phenomenon (Petty, Thompson, \& Stew, 2012). Bracketing allows the researcher to mitigate the potential harmful effects of unacknowledged preconceptions to increase the rigor of the research study (Tufford \& Newman, 2012). I did not know the SME business owners to mitigate personal bias during the interview. To mitigate personal bias, I controlled the reactions to the interview responses during the online Skype interviews. Yin (2014) noted that an interview protocol allows the researcher to keep track of the data collection process. I also followed the interview protocol with each participant to ensure that I did not miss or skip any important steps during the interview process. The interview protocol is available at Appendix B. My case 
study protocol consisted of (a) an overview of the case study, (b) data collection procedures, (c) data collection questions, and (d) a guide for the case study report.

After the interviews, I used member checking to confirm the responses of the participants as recorded during the interview. I also synthesized the interview data and called the participants to ask them whether the synthesis represented the answers to the questions. Member checking ensures that one has captured the accurate meaning and voice of the interview recordings (Houghton, Casey, Shaw, \& Murphy, 2013).

\section{Participants}

Kenya SME business owners were the focus of this qualitative multiple case study. The target population comprised four Kenya SME owners of businesses located in Kakamega Town, Kenya, and who have had access to credit to improve company profitability and growth within the past 5 years. The first step in conducting the interviews was to create a list of potential participants from Kenya SMEs. I then contacted the participants and explained the purpose of the study. I asked each participant if the participant had gained access to credit to improve company profitability and growth within the past 5 years. If the participant said "yes" to my question and agreed to participate, I then sent an e-mail to the participant containing the interview questions and the consent form. Gaining access to participants was challenging, especially where geographical barriers existed between the potential participants and me. I used friends as a strategy to gain access to potential participants after getting the approval from the IRB. Smith (2012) argued that the researcher's personality and skills and the dynamics of the participant organization influence access to the study participants. I chose Kakamega Town because most of my long-term friends live there, and it is the headquarters of 
Kenya's sugar industry. Based on these relationships, I was able to gain access to the targeted population through friends. After the IRB approval, I made phone calls to the four SME business owners to introduce myself and ask for their participation in the study. The relationships I had with my friends assisted in building a working relationship with the potential research participants. I also obtained the participants' electronic signature on the consent form before conducting the interviews. I e-mailed the participants the letter of invitation explaining the intent of the study and included the participant consent form for the participant to review and sign electronically by replying $I$ consent to the e-mail. Additionally, I gave each participant a unique identifier to protect his or her privacy. Damianakis and Woodford (2012) argued that researchers must protect participants and others named in their narratives from potential harm associated with the study without disclosing who they are. The participants selected aligned with the research question to achieve the objective of the study. The overarching research question for this study was: What strategies do some Kenyan SME business owners use to access credit to improve company profitability and growth? Qualitative research allows the researcher to align the evidence with the initial research question to make analytical conclusions (Yin, 2014).

\section{Research Method and Design}

\section{Research Method}

I selected a qualitative research method for this study. According to Hazzan and Nutov (2014), qualitative research methods help researchers to study social phenomena, situations, and processes that involve people, illuminating them from a variety of perspectives. A qualitative research method and case study design enable the researcher 
to explore the meaning and experiences of individuals or groups regarding a particular phenomenon within a natural setting. In this study, I used a qualitative multiple case study design approach to explore the strategies some Kenya SME business owners used to access credit to improve company profitability and growth.

Qualitative inquiry means staying inductively open to the unknown while exploring and seeking information to enhance a deeper understanding of the social phenomena (Kaczynski et al., 2013). A qualitative research method provides the researcher with a framework for obtaining an in-depth understanding of the problem from the participants' perspective. The nature of the study aligned with the qualitative research method more than the quantitative because of the exploratory nature of the topic. Anyan (2013) argued that quantitative research methods focus on numerical data expressions and volume of data collected. Therefore, I did not use quantitative or mixed methods because the purpose of the study was to obtain an in-depth understanding of the phenomenon, and not statistical information.

\section{Research Design}

Qualitative research methodologies include case study, narrative, ethnography, and phenomenology. For this study, I used the case study design method to explore the strategies some Kenyan SME business owners used to access credit for their businesses. The case study design is an exploration of a bound system through in-depth data collection, each study with its particular sampling and analysis strategies (Boblin et al., 2013). The case study design allows the researcher to obtain a better understanding of a specific or complex social problem through the interview, observation, and documentation techniques (Petty et al., 2012). The design is the logical sequence that 
connects the empirical data to a study's initial research questions and its conclusions (Yin, 2014). Additionally, an exploratory case study design allows the researcher to ask the why and what of the study to obtain in-depth information about the phenomenon. I did not use narrative research, ethnography, or phenomenology because they do not provide an in-depth understanding of the problem. Narrative research focuses on the detailed stories or personal reflection of events from one or more individuals (Petty et al., 2012). The intent of this study was to understand the strategies some Kenyan SME business owners used to obtain credit, and not to tell personal stories. I did not use ethnography because it contains guidance for capturing the cultural aspects of the research participants and not business problems. Ethnography contains instructions the researcher can use to examine the shared patterns of behavior, beliefs, and language within a cultural group (Petty et al. 2012). Researchers use phenomenological design to capture the worldviews and lived experiences of individuals relevant to the phenomenon (Moustakas, 1994). I did not select the phenomenological design because I was not studying the worldviews and lived experiences of individuals. The focus of this study was to explore the strategies some Kenyan SME business owners used to access credit to improve company profitability and growth, and not the lived experience of individuals.

I transcribed the interview data and shared the findings with the participants through e-mail to allow them to make any corrections to enhance the reliability and validity of the findings. Qualitative researchers often make decisions related to the adequacy of their sample based on the notion of data saturation ( $\mathrm{O}^{\prime}$ Reilly \& Parker, 2013). I also used member checking to confirm the responses of the interview recordings. Member checking ensures that the researcher has captured the accurate meanings and 
voice of the interview recordings (Houghton et al., 2013). I continued interviewing until no new themes emerge.

\section{Population and Sampling}

The research design was a qualitative multiple case study concerning Kenyan SME businesses. The sample population consisted of four Kenyan SME owners of businesses located in Kakamega Town, Kenya, who have had access to credit to improve company profitability and growth within the past 5 years. The sampling method was purposeful by selecting participants based on the selection criteria. The selection criteria required that each participant be a Kenyan SME business owner who had access to credit to improve company profitability and growth within the past 5 years. According to Poulis, Poulis, and Plakoyiannaki (2013), researchers use purposeful sampling to maximize and integrate additional methodological tools to provide a context-sensitive sampling framework. Purposeful sampling helps provide the researcher with the rationale for studying unknown populations of social phenomena (Marton, 2013).

I used Skype interview technique to collect data from SME business owners. Qualitative researchers can use Skype technique to record both the visual and the audio interaction of the interviewees through simple software loaded onto their workstation (Hanna, 2012). Qualitative researchers often make decisions related to the adequacy of their sample based on the notion of saturation (O’Reilly \& Parker, 2013). Achieving data saturation is essential to the success of qualitative studies. The quality of interviews, the number of interviews per participant, sampling procedures, and researcher experience all influence data saturation (Marshall, Cardon, Poddar, \& Fontenot, 2013). 
In this study, I used member checking to ensure the accuracy of the interview recordings. Member checking allowed me to seek any clarification from the participants and thereby minimize the incidence of incorrect data to ensure the accuracy of data. Member checking ensures that the researcher has captured the meanings and voice of the interview recordings (Houghton et al., 2013). I continued interviewing until I reached data saturation. Data saturation is defined as the point at which no emerging themes are found from the reviewing of successful data regarding the phenomenon (Ando, Cousins, \& Young, 2014). To ensure data saturation, I continued interviewing until no new themes emerged. In addition to member checking, I transcribed the interview data and shared the findings with the participants through e-mail to allow them to make any corrections to enhance the reliability and validity of the findings. The use of purposive sampling allowed me to obtain in-depth information about the strategies some Kenya SME owners used to access credit to improve company profitability and growth within the past 5 years.

\section{Ethical Research}

I conducted this study after receiving approval from the IRB at Walden University with the required approval number \# 04-28-16-0427758. The IRB approval ensures the researcher adheres to ethical values regarding human research participants in the study.. The ethical review system encourages researchers to reflect on their research process from the perspective of all the possible stakeholders including participants and others involved in their lives, institution, and potential future users of the research findings (Wiles \& Boddy, 2013). The IRB expect researchers to develop ethical protocols that outline their study aims and activities, and to specify the risks and benefits for 
participants (Damaniakis \& Woodford, 2012). I followed the three basic principles that are relevant to the ethics of research involving human subjects (a) respects for persons, (b) beneficence, and (c) justice (Belmont Report, 1979). I fully understood the ethical considerations regarding protection of human participants in the study. To achieve the ethical standards, I treated the participants with respect and dignity to build trust to ensure a proper researcher-participant working relationship. Donnelly, Gabriel, and Ozkazanc-Pan (2013) noted that recognizing the emotions and dilemmas involved in the research can make the researcher treat participants with respect, protect them from harm, and save them from embarrassing exposure. Ethical researchers need to obtain informed consent from study participants and protect the privacy and confidentiality of the participants from potential harm (Yin, 2014).

Each participant had to sign the consent form electronically before participating and answering the interview questions. The Participant Consent Form includes information that informs the participant about the research topic, risks, and benefits of being in the study. Although all the participants understood English, I had to give them a call to ensure they understood the consent form and to clarify any questions. To ensure confidentiality, I did not use the participants' names or their businesses in the study. I gave each participant a unique number to maintain confidentiality. Wiles, Coffey, Robinson, and Heath (2012) argued that the researcher's inability to predict the impact of identification provides an appropriate rationale for anonymizing participants to protect them from possible future harm. The consent form also included the phone number of a Walden University representative, so that, if necessary, the participants could call the representative in private to discuss their rights as participants. I conducted an online, 
face-to-face Skype interview to obtain an in-depth understanding of the strategies some Kenya SME business owners used to access credit to improve company profitability and growth. A qualitative researcher can use the Skype technique to record both the visual and audio interaction of the interviewees through simple software downloaded onto their station (Hanna, 2012). I also made the participants aware that contributing in the study was voluntary. The Participant Consent Form clarified that their participation in the study was voluntary, and they could withdraw at any time without penalty. The participants could withdraw from the study at any time by emailing me. I did not provide any incentives for participating in this study, but each participant did have access to the report of the findings, which I emailed them. To enhance validity, I emailed each participant a copy of the transcript for review and verification of their responses as recorded during the interviews. All data collected was stored in a locked safe for five years before disposal to ensure confidentiality.

\section{Data Collection Instruments}

Qualitative researchers can obtain case study evidence from any of the six sources: documentation, archival records, direct observation, interviews, participantobservation, and physical artifacts (Yin, 2014). In this qualitative multiple case study, I was the data collection instrument. In-depth, face-to-face semistructured interviews and company documentation in the form of cash flow and profit and loss statements were the two primary sources for data collection. I conducted online, face-to-face semistructured interviews with four Kenya SME business owners using Skype technique to obtain an indepth understanding of the strategies they used to access credit to sustain their businesses. The use of Skype technique allows the researcher to record both the visual and audio 
interaction of the interviewees through simple software downloaded onto their workstation (Hanna, 2012).

I ensured each participant has read and signed the informed consent form electronically before beginning the interview process. I also attached the consent form and interview questions to the appendices as required. The interview questions are available in Appendix A and listed in the table of contents. I also developed and followed the case study protocol. A case study protocol aided me in keeping the focus on my topic and assisted in reliability. My case study protocol consisted of (a) an overview of the case study, (b) data collection procedures, (c) the data collection questions, and (d) a guide for the case study report (Yin, 2014). The use of company documents in the form of cash flow and profit and loss statements was supplemental data to the interviews.

After the interviews, I used member checking to ensure the accuracy of the interview recordings. Member checking ensures that the researcher has captured the accurate meaning and word choice (Houghton et al., 2013). In addition to member checking, I emailed each participant a transcript of the interview recordings and asked them to look for any errors or missing information to ensure the accuracy of the interview data. I also asked each participant to email copies of company documentation in the form of monthly cash flow and profit and loss statements as supplementary data for analysis. Yin (2014) found that case studies using multiple sources of evidence have high quality than those that rely on a single source of information.

\section{Data Collection Technique}

The data collection techniques for this study were interviews and company documents in the form of cash flow and profit and loss statements. According to Rowley 
(2012), qualitative researchers use interviews to gain an understanding of opinions, attitudes, experiences, processes, behaviors or predictions of the research topic they are interested in collecting data. Yin (2014) provided three types of interviews for a case study design: in-depth (prolonged) interviews, shorter interviews, and survey interviews. For this study, I conducted face-to-face, semistructured interviews in accordance with the interview protocol (Appendix B).

The first step in conducting the interviews was to create a list of the potential participants from Kenya SMEs, and then contacted the participants and explained the purpose of the study. I emailed the interview questions along with the consent form as listed in Appendix A to each of the participants. To ensure accurate, in-depth responses, I arranged to speak with the four Kenya SME business owners before the formal interview. Qualitative researchers commonly use interview technique to help collect data in their studies. The qualitative semistructured interview modes include face-to-face and telephone (Irvine, Drew, \& Sainsbury, 2013). In this study, I used face-to-face in-depth semistructured interviews to collect data from some Kenya SME business owners. The advantage of these semistructured interviews is that it allows the researcher to ask questions to explore the main question sufficiently (Rowley, 2012). Additionally, the semistructured interviews allow one to change the question order to accommodate the participants. However, the disadvantage of the semistructured interviews is that the researcher has to limit the number of questions based on the interview schedule (Rowley, 2012). Despite the disadvantage, semistructured interviews allow the researcher to explore in-depth information about the phenomenon by asking probing questions. In this study, I used face-to-face semistructured Skype interviews to collect data from Kenya 
SME business owners. As a free communication technique, Skype interview provides the researcher with an opportunity to interview those participants who have time and space limitations (Hanna, 2012). Member checking allows one to verify the accuracy of the data from the interview recordings to ensure the validity of the study (Harper \& Cole, 2012). I continued interviewing until there were no new themes emerging. Additionally, I transcribed the interview data and shared the findings with the participants through email to allow them to make any corrections to enhance the reliability and validity of the findings. I also examined each SME business owner's documents in the form of monthly cash flow and profit and loss statements to obtain in-depth information about the strategies some SME business owners used to access credit to improve company profitability and growth.

\section{Data Organization Technique}

In this study, I used the player audio record option on my laptop to record the participant interviews during the interview process. I also had a hand help audio recorder for back up. I tested the operational functionality of both the devices before conducting an online interview through Skype technique to ensure they worked properly, and that the audio was loud and clear to facilitate transcription later. The use of Skype technique enabled me to record both the visual and audio interaction of the interviewees (Hanna, 2012). I utilized the reflective journal to take notes on critical comments during each interview in addition to the audio recording. A reflective journal allows the researcher to record the thoughts about the decisions made during the interview process to enhance dependability and transparency (Houghton et al., 2013). After the interviews, I asked the participants to email the company documents in the form of cash flow and profit and loss 
statements as supplementary data for analysis. I also perform data cleansing to remove all irrelevant data that did not align with the search criteria. Adu-Manu Sarpong and Arthur (2013) described data cleansing as the process of detecting the errors and inconsistencies in data to enhance the quality of data. After data cleansing, I used the NVivo software program to code and analyze the data. I ensured the collection and storage of all data aligned with IRB requirements, and that I am the only person who has exclusive access to the raw data. The IRB requires all researchers to reflect on their research process from the perspective of all the stakeholders including participants, institution, and potential future users of the research findings (Wiles \& Boddy, 2013). For this study, I used alphanumerical codes to mask each participant's identity. I assigned each participant an identity number preceded by the letter $\mathrm{p}$ such as Participant 1 , Participant 2 , and Participant 3. To ensure confidentiality, I saved all the collected data on a secured hard drive and kept it for five years before disposal as required by Walden University.

\section{Data Analysis}

Qualitative case study researchers can triangulate data from multiple sources such as documentation, interviews, direct observations, participant-observation, and physical artifacts to support their research studies (Yin, 2014). Data triangulation allows a qualitative researcher to collect information from multiple sources to corroborate the same finding (Yin, 2014). To explore the strategies some Kenya SME business owners used to access credit to improve company profitability and growth, I used the interview questions to address the central research question. Qualitative interviews allow researchers to capture the voices of the participants to obtain insights into the phenomenon (Onwuegbuzie \& Byers, 2014). I asked the participants to email me the 
company documents in the form of monthly cash flow and profit and loss statements as supplementary data for analysis. Methodological triangulation provides the researcher with a more comprehensive and quality evidence than relying on a single source of information (Yin, 2014). The overarching research question for this study: What strategies do some Kenya business owners use to access credit to improve company profitability and growth? I used the following interview questions to address the central research question:

1. What strategies do you use to access credit for your business?

2. What are the main challenges to accessing credit for your business?

3. How does your relationship with other business owners help access credit to sustain your business?

4. How do you describe your relationship with the banks?

5. How does access to information help you to obtain credit for your business?

6. How does accessibility to credit affect the performance of your business?

7. What else would you like to share about your experience of how to access credit for your business?

I used transcript review to ensure the accuracy and validity of the data. I transcribed the interview data and shared the findings with the participants through email to allow them to make any corrections to enhance the reliability and validity of the findings. In addition to transcript review, I conducted member checking to confirm the responses of the interview recordings. Member checking ensures that the researcher has captured the accurate meanings and voice of interviews (Houghton, Casey, Shaw, \& Murphy, 2013). I continued interviewing until there were no new themes emerging. After 
the participants had confirmed the accuracy of the data, I used the NVivo tool to analyze and code data. I used a data cleansing technique to remove all the irrelevant data that did not conform to the search criteria. The data cleansing process allows the researcher to detect the errors and inconsistencies in data to enhance the quality of information (AduManu Sarpong \& Arthur, 2013). I created unique alphanumerical codes for the participants such as Participant 1, Participant 2, and Participant 3, to help distinguish between participants, and maintain their confidentiality. Coding allows the researcher to index the texts containing raw data into codes to signify the occurrence of specific information assigned to segments of the text (Glaser \& Laudel, 2013). Using codes allowed me to retrieve the text segments and group them on a thematic basis to address the research question.

In this research study, I used the social capital theory (SCT) to explore the strategies some Kenya SME business owners used to access credit to improve company profitability and profitability. I also used the three constructs of the social capital theory (a) structural capital, (b) relational capital, and (c) cognitive capital to structure the interview questions concerning the strategies some Kenya SME business owners used to access credit for their businesses. The three constructs of the social capital theory helped understand the context of this research study and I used the key themes to correlate to prior literature.

\section{Reliability and Validity}

In this section, I will discuss the reliability and validity aspects of the study. Reliability refers to the degree to which different researchers use multiple applications of the same instrument to ensure consistency of the findings (Goffin, Raja, Claes, 
Szwejezewski, \& Martinez, 2012). Validity refers to the criterion for evaluating the quality and acceptability of research (Zohrabi, 2013). For case studies, Yin (2014) recommended the use of multiple sources to enhance the reliability and validity of the study findings

\section{Reliability}

Ensuring reliability in quantitative studies is different from qualitative studies. Quantitative researchers measure reliability because the data are in numerical form while qualitative researchers find it difficult to measure reliability because the data are in narrative form and subjective (Zohrabi, 2013). In quantitative research, there is control and manipulation of variables of the study, whereas, in qualitative research, control and manipulation may distort the natural occurrence of phenomena (Oluwatayo, 2012). Qualitative researchers address the consistency of the participants' responses and their relevance to the phenomenon, whereas quantitative researchers use statistical tools to measure the study results. The analogous criteria for qualitative research study comprise dependability, credibility, transferability, and confirmability. These criteria are not measurable and require the qualitative researcher to use member checking and transcript review to ensure reliability and validity of the study.

Dependability relates to the extent to which the researchers replicate the study findings with similar participants in similar conditions (Cope, 2014). Qualitative case study researchers can use member checking and transcript review strategies to ensure consistency and reliability of their findings. After the interviews, I conducted member checking to confirm the responses of the interview recordings. Member checking ensures that the researcher has captured the accurate meanings and voice of the interviews 
(Houghton et al., 2013). I also synthesized the raw data and called each participant to ask them if the synthesis represented the answer to the interview question. Synder (2012) used member checking to confirm the participants' responses before honing the findings of the study. I continued interviewing until no new themes emerged. Afterward, I transcribed the interview data and shared the findings with the participants through email to allow them to make any corrections to enhance the reliability and validity of the findings. The use of purposive sampling helped obtain in-depth information about the strategies some Kenya SME business owners used to access credit to improve company profitability and growth.

Validity

Member checking allows the researcher to enhance the accuracy, credibility, and validity of the study results (Harper \& Cole, 2012). I continued interviewing until no new themes emerged. Credibility relates to the truth of the data as interpreted and represented by the researcher. Qualitative researchers enhance credibility by sharing and verifying the study findings with the participants (Cope, 2014). I also transcribed the interview data and shared the findings with the participants through email to allow them to make any corrections to enhance the reliability and validity of the findings. In addition to the interview data, I asked each participant to email company documents in the form of cash flow and profit and loss statements as supplementary data for analysis. Yin (2014) noted that case studies using multiple sources of evidence have high quality than those that rely on a single source of information. The methodological triangulation of both the interviews and company documents as sources of data helped to enhance the credibility of the findings. 
Transferability relates to the provisioning of the researcher's database to enable other researchers to transfer the findings to other settings (Marton, 2014). Qualitative researchers should provide in-depth information about the participants and research context to allow the reader assess the transferability of the findings (Cope, 2014). However, the transferability of the findings will depend on the intent of the research. In a case study, the goal of the researcher is to make analytical conclusions, and not extrapolate statistical generalizations (Yin, 2014). In this study, I used the findings to obtain an in-depth understanding of the strategies some Kenya SME business owners used to access credit to improve company profitability and growth.

Qualitative researchers need to confirm their data to ensure the accuracy of the findings. The confirmation process facilitates the comparison of data from multiple sources to ensure verification of the findings (Houghton et al., 2013). I confirmed the data by running the frequencies of words and themes within NVivo software. In this study, I utilized methodological triangulation, transcript reviews, and member checking to achieve data saturation and enhance the credibility of the study results.

\section{Transition and Summary}

In Section 2, I restated the purpose statement of my research study, addressed the role of the researcher, discussed the selected participants, and detailed the research methodology and design. Next, I described the population and sampling method, ethical research, data collection instruments, technique, and organization and data analysis techniques. I concluded Section 2 with a discussion of the methods and techniques to ensure reliability and validity of my study. 
Section 3 begins with an introduction including the purpose statement, the research question, and the presentation of the findings. Section 3 further includes (a) application to professional practice, (b) implications for social change, (c) recommendations for action, (d) recommendations for further research, (e) research reflections, and (f) summary and study conclusion. 
Section 3: Application to Professional Practice and Implications for Change

In Section 3, I provide the findings of the study on the strategies that some SME business owners use to access credit to improve company profitability and growth within 5 years. Section 3 also comprises (a) an overview of the study, (b) presentation of findings, (c) application to professional practice, and (d) implication for social change. Additionally, section 3 includes recommendation for actions, recommendations for further research, research reflections, and summary and study conclusion.

\section{Introduction}

The purpose of this qualitative multiple case study was to explore what strategies some Kenyan SME business owners used to access credit to improve company profitability and growth within the past 5 years. SME business owners make a significant contribution to the Kenyan economy. Formal SMEs contribute up to $40 \%$ of the private sector workforce and 33\% of GDP to the Kenyan economy and are the engine of economic growth (Mwangi et al., 2013). Despite their significant contributions, SME business owners face challenges in accessing credit to improve company profitability and growth. Lack of access to financial resources contributed to the slow growth and failure of SMEs (Moyi, 2013). Majority SME business owners were unable to access credit because of the huge collateral demanded by banks as a condition for lending.

\section{Overview of Study}

The participants were SME business owners who satisfied the selection criteria that each participant be a Kenyan SME business owner who had access to credit to improve company profitability and growth within the past 5 years. I conducted semistructured interviews with four SME business owners in Kakamega Town, Kenya, 
via Skype. The use of Skype technique allows a researcher to record both the visual and audio interaction of the interviewee (Hanna, 2012). To protect the confidentiality of the participants, I did not use their actual names. The methodological triangulation of data included the transcribed interview data and company documentation. I emailed each participant a copy of the transcript for review and verification of their responses as recorded during the interviews. Once I reached data saturation, I uploaded the transcribed data into NVivo 11 plus, a qualitative software tool, to aid me in identifying the key strategies to answer the overarching research question. Based on the methodological triangulation of the semistructured interviews and company documentation, the emergent themes identified were (a) group lending, (b) educational and professional background of the enterpreneur, (c) information access, and (d) effect of access to credit on the performance of SMEs. The following are the results of the data analysis from the interviews with the four SME business owners.

\section{Presentation of the Findings}

The overarching research question for this study was: What strategies do some Kenyan SME business owners use to access credit to improve company profitability and growth? SME business owners contribute significantly to the Kenyan economy providing about $75 \%$ of the general employment and approximately $18 \%$ of GDP (Kung'u, 2015). However, SME business owners face challenges in accessing credit to improve company profitability and growth because of inadequate collateral. Banks demand higher collateral requirements for SME loans because of the credit risk. (Onyango \& Achieng, 2013). I used semistructured interviews and business documentation to explore the strategies that 
some SME business owners used to access credit within the past 5 years to improve company profitability and growth.

The participants in this study were four SME business owners including (a) a computer services owner, (b) a printing and stationery store owner, (c) a motorbike service owner, and (d) a bar and restaurant owner. All the participants were located in Kakamega Town, Kenya, and had access to credit within the past 5 years. After the IRB approval, I arranged for phone calls with the four SME business owners to introduce myself and ask for their participation in the study. I sent four invitation letters to potential participants through e-mail, and the four agreed to take part in the study. I collected data using semistructured interviews via Skype and reviews of company documentation. I asked each of the participants seven semistructured, open-ended interview questions using the interview protocol (Appendix B) as a guide. All four participants responded to all seven of the interview questions. Concluding the interview, I asked each of the participants to e-mail me their company profit and loss statements and cash flow statements as supplementary data for analysis. In closing, I thanked them for their participation in my research study. I then transcribed the data and e-mailed a copy to each of the participants for review and verification of the interview responses. Once I achieved data saturation, I entered the transcribed data into NVivo 11 Plus for coding and analysis. Qualitative researchers often make decisions related to the adequacy of their sample based on the notion of data saturation (O’ Reilly \& Parker, 2013). The following four main themes emerged from the data analysis: (a) group lending, (b) information access, (c) education and professional background of the entrepreneur, and (d) effect of access to credit on the performance of SMEs. 
The first theme that emerged involved the importance of group lending as a strategy by SME business owners to access credit for their businesses. The second emergent theme was the use of information to access credit to sustain their businesses. The third emergent theme revealed education and professional background of the entrepreneur as a strategy for accessing credit. The fourth emergent theme involved the effect of access to credit on the performance of SMEs. These four emergent themes align with my conceptual framework, the social capital theory as developed by Hanifan (1916). Hanifan described how members of the rural school community used their social capital to help improve the school performance. Later several theorists used the theory to explain how poor people accumulate their social capital to access resources to achieve a common purpose. In developing countries, poor entrepreneurs form networks to access information and financial resources to improve business performance (Woolcock \& Narayan, 2000). The responses from all the participants supported the assumption that SME business owners can use group lending as a strategy for accessing credit to improve the profitability and growth of their businesses.

\section{Emergent Theme: Group Lending}

Responses for group lending originated from Question 1, in which I explored the strategies that SME business owners used to access credit to improve company profitability and growth. Group lending mechanisms allow members to screen, monitor, and enforce each other's loan habits, which facilitates further credit (Kiragu \& Sakwa, 2013; Naveen, 2012; Nawai \& Shariff, 2013). All the participants (100\%) mentioned that they used group lending as a strategy to access credit to sustain their businesses (Table 2). Participant 1, Participant 2, and Participant 3 (75\%) said that group lending mechanisms 
allow them to access credit from the government in the form of Youth Fund. Youth Fund is an interest-free loan given to individuals between 18 and 35 years old who belong to a registered group. The Youth Fund allows the youth to obtain funds directly either as individuals or organized entities (Okoth et al., 2013). SME business owners who join groups can guarantee one another, thereby gaining access to credit to sustain their businesses. Networking among groups allow businesses to gain access to resources that might otherwise not be available to them (Mwaura, Gathenya, \& Kihoro, 2015). Group members can access credit from microfinance institutions (MFIs) such as Kenya Women Finance Trust (KWFT). According to Ouma and Rambo (2013), 95\% of the SMEs experienced higher sales and better profits after accessing credit from KWFT. However, all the participants agreed that it was difficult to access bank credit because of the stringent collateral requirements and high-interest rate that is currently $19-24 \%$ per annum. Lack of adequate collateral was a major obstacle to SME lending by banks (Onyango \& Achieng, 2013). The responses from all participants indicated that SME business owners should join groups to help access credit from other sources. The following are the characteristics of group lending:

- The individual and not the group receive the loan.

- Members make weekly savings of a minimum of Kshs 200 (\$2), to a Community Development Programme (CDP) account affiliated with the group.

- A maximum of a third of the number of group members receive a loan at a time. 
- For a loan to an individual, that individual's shares must be equivalent to a third of the requested loan amount.

- Group members use their collective shares as collateral for the individual loans.

- Members guarantee one another of repayment and in the case of default, share joint liability.

According to Kiragu and Sakwa (2013), SME business owners who use group lending as a strategy can access credit and improve repayment rates, thereby gaining access to further credit.

Table 2

Frequency of Group Lending Strategy Mentioned

\begin{tabular}{ccc}
\hline Source & $\begin{array}{c}\text { Number } \\
\text { of times } \\
\text { mentioned }\end{array}$ & Percentage \\
\hline Participant 1, Question 1 & 2 & 28.57 \\
Participant 2, Question 1 & 1 & 14.28 \\
Participant 3, Question 1 & 2 & 28.57 \\
Participant 4, Question 1 & 2 & 28.57 \\
\hline
\end{tabular}

\section{Emergent Theme: Education and Professional Background}

The theme of education and professional background originated from Question 1, in which I explored the strategies that SME business owners use to access credit for their businesses. Although education and professional background were not part of this study, the findings indicate that SME business owners with education and salaried jobs were 
more likely to access bank loans than those who only have an education. Being a salaried employee is considered collateral for accessing a bank loan. According to Hassan and Mugambi (2013), there is a direct positive relationship between financial resources and educational level of the entrepreneur. The first interview question revealed that one of the four participants had no college education, and three participants had completed their college education with a Bachelor's degree (Table 3). Two of the three participants with a college education have salaried jobs. All the participants were high school graduates. Participant 3 and Participant 4 agreed that being a salaried employee allows one to access bank credit through a check-off system. The following are the requirements for accessing a bank loan as a salaried employee:

- Provide proof of personal identification.

- Provide employer information such as the name of employer, location, and job title to facilitate check-off system.

- Provide paystubs as a proof of being in a salaried job position.

- Provide guarantors who must be from the same pay point as the borrower.

- Show proof of some property as collateral in case of default.

- The salaried employee agrees to sign and pay additional costs for death insurance as a means of repayment in the event of death.

However, Participant 3 and Participant 4 said that they were unable to receive a sufficient loan because of their minimum salary. The participants argued that long processing time, high-interest rates, and unwilling guarantors were constraints to gaining access to bank credit. Stringent lending requirements such as collateral and application procedures limit access to bank credit (Onyango \& Achieng, 2013). 
Table 3

Educational and Professional Background of the Participants

\begin{tabular}{lll}
\hline Participant Response & Number & Percentage of Total \\
\hline High School Graduate & 4 & $100.0 \%$ \\
No college & 1 & $25.0 \%$ \\
Completed College & 3 & $75.0 \%$ \\
\hline
\end{tabular}

\section{Emergent Theme: Information Access}

The theme of information access originated from Question 5, in which I explored the participants' insight into how information helps them to access credit for their businesses. All the participants shared similar thoughts about the importance of information access as a strategy for obtaining credit for their businesses (Table 4). According to Njeru, Nyangaresi, and Waithaka (2013), access to information allows SME business owners to access credit to exploit business opportunities. All the participants $(100 \%)$ agreed that access to information helps the seekers identify where to obtain credit at affordable interest rates and with fewer collateral requirements. Participant 1 and Participant 3 also agreed that access to information has helped them understand the importance of keeping proper business records to facilitate access to credit. The following are some of the sources of information regarding access to credit.

- Business training and seminars.

- Print and electronic media.

- Lectures through church organizations. 
All the participants seemed to agree that access to information was important to help them understand where to obtain credit and the collateral requirements, interest, and repayment rates.

Table 4

Frequency of Information Access Strategy Mentioned

\begin{tabular}{lll}
\hline Source & Number of times mentioned & Percentage \\
\hline Participant 1, Question 5 & 3 & 37.5 \\
Participant 2, Question 5 & 1 & 12.5 \\
Participant 3, Question 5 & 2 & 25.0 \\
Participant 4, Question 5 & 2 & 25.0 \\
\hline
\end{tabular}

\section{Emergent Theme: Effect of Access to Credit on Performance of SMEs}

The theme effect of access to credit on the performance of SMEs originated from Question 6, in which I explored how accessibility to credit by SME business owners affects the performance of their businesses. Responses from all participants (100\%) indicated that access to credit helps boost sales, purchase additional business assets, hire more employees and provide quicker customer service. All the participants agreed that their sales increased by between $30-50 \%$ after receiving the loan (See Table 5). Also, Participant 1 and Participant 2 said they had no employee before taking the loan but after taking the loan, they had to hire one to assist in the business. Participant 3 had two employees but after taking the loan and acquiring three more motorbikes, he had to hire three more employees. Participant 4 had one employee but after the loan, he had to hire two more employees to attend to the increased number of customers in the bar and restaurant. The responses from all the participants indicate that access to credit has a 
positive impact on the performance of SMEs. According to Bunyasi, Bwisa and Namusonge (2014) and Osoro and Muturi (2014), access to credit has a positive effect on the financial performance and growth of SMEs. However, Moyi (2014) indicated that there was no correlation between credit and growth of SMEs. The author argued that the credit constraint variable has a significant effect when interacting with other variables such as access to technology and formality of business. Despite the limitation, access to credit helps improve the profitability and growth of SMEs. SME business owners who have access to credit are more likely to improve their profitability and growth than those who have no access.

Table 5

Increase in Sales after the Loan

\begin{tabular}{ll}
\hline Source & Percentage \\
\hline Participant 1, & $30 \%$ \\
Participant 2, & $40 \%$ \\
Participant 3, & $30 \%$ \\
Participant 4 & $50 \%$ \\
\hline
\end{tabular}

\section{Summary of Themes}

The findings indicate that if SME business owners are educated and have an active professional background and adhere to two strategies that include (a) group lending, and (b) effective use of information access they may be able to access credit to improve the profitability and growth of their businesses. The conceptual framework for this study was the social capital theory. An individual joins a group to fill a structural hole by providing social capital as well as benefit from the same that provided by other 
group members (Kilele, Nduruhu, \& Kimani, 2015). By using the social capital construct, I was able to identify and prioritize the strategies that SME business owners might use to access credit to sustain their businesses. Nahapiet and Ghoshal (1998) developed three constructs of social capital theory (a) structural, (b) relational, and (c) cognitive to describe how firms combine and exchange resources to achieve a common goal. Business leaders can combine these constructs to improve their intellectual capital and value addition, which would not otherwise be possible. Social capital allows individuals to establish relationships based on norms and trust to reduce transaction costs, thereby gaining access to credit (Ong'indo, 2014). People who trust one another and work together, are more likely to share knowledge and experiences to achieve a common goal. Jonsson and Lindbergh (2013) used the cognitive construct of social capital to explain how members of a network share language and systems of meaning to access information and resources, which they could not otherwise obtain. The findings indicate that one strategy alone is not enough for accessing credit to improve the profitability and growth of the business, which aligns with the social capital theory, because social capital theory requires the combination of three constructs (a) structural, (b) relational, and (c) cognitive to achieve a common goal (Nahapiet \& Ghoshal, 1998). The four main emergent themes that discussed were (a) group lending, (b) information access, (c) education, and professional background of the entrepreneur, and (d) effect of access to credit on the performance of SMEs. Understanding the common themes and patterns leads to a better understanding of the phenomenon and solutions. 


\section{Application to Professional Practice}

The purpose of this study was to explore the strategies that some SME business owners used to access credit to improve company profitability and growth within the past 5 years. The findings include the evidence from participants, analysis of the data, and interpretation of the results. Group lending, education and professional background of the entrepreneur, information access, and the effect of access to credit on SME performance findings are relevant to the professional SME business practice. The findings and recommendations may serve as a basis for SME business owners to improve the strategies of accessing credit leading to the growth and development of the SME sector of the Kenyan economy. The results could guide SME business owners with financial constraints as they improve strategies to access credit. In professional practice, the results include the potential for SME business owners to share best practices for improving access to credit. This study contributes to the body of entrepreneurial literature to benefit both the current and future business owners in the SME sector. SME business owners may review (a) the group lending, (b) the education and professional background of the entrepreneur, (c) the information access, and (d) the effect of access to credit on the performance of SMEs to implement strategies for accessing credit to improve company profitability and growth. SME business owners contribute about $75 \%$ of general employment and approximately $18 \%$ of gross GDP to the Kenyan economy (Kung'u, 2015).

SME business owners that recognize the importance and need to form groups might have the advantage in accessing credit to improve the profitability and growth of their businesses. Group lending mechanisms facilitate access to credit as members screen, 
monitor and enforce each other's loans, which in turn improves repayment rates (Kiragu\& Sakwa, 2013). The findings are relevant to professional practice; the study contains information regarding how to access credit to improve company profitability and growth. Access to information facilitates contact to financing professionals, which in turn improves business performance (Bunyasi, Bwisa, \& Namusonge, 2014). In turn, (a) the business generates income for owners and their families, (b) allows employees keep their jobs, (c) enhances community standards of living, and (d) improves the economy. Small and medium enterprises (SMEs) play an important role in the Kenyan economy (Kisaka \& Mwewa, 2014).

\section{Implications for Social Change}

The implications for social change from the doctoral study include the potential for SME business owners to share best practices for accessing credit to improve company profitability and growth. Successful business owners contribute significantly to strengthen the Kenyan economy through profitability and growth of the SME sector. I anticipate that knowledge offered in this study would (a) aid SME business owners to improve access to credit, (b) benefit aspiring SME business owners in developing strategies to access credit.

Also, such knowledge would include suggestions on strategies for SME business owners to access credit and ensure sustainable business growth to enhance community standards of living. Development of strategies for accessing credit by SME business owners through the implementation of recommendations may generate employment, reduce poverty and contribute to the Kenyan economy. SME business owners may use the findings from the study to expand the business, which in turn leads to a reduction in 
the unemployment rate and crime in Kakamega Town. The findings from this study may also help creditors and relevant government agencies to understand the challenges that SME business owners face in accessing credit to sustain their businesses. Successful business owners could create economic empowerment in Kakakega Town that could allow residents to realize their dreams of financial security to improve the quality of life for Kenyans. If the SME business owners access credit to sustain business profitability and growth, it will contribute to the creation of jobs, reduction of poverty and enhance community standards of living.

\section{Recommendations for Action}

The purpose of this qualitative multiple case study was to explore what strategies some Kenya SME business owners used to access credit to improve company profitability and growth within the past 5 years. SMEs contribute about $75 \%$ of general employment and approximately 18\% of GDP in the Kenyan economy (Kung'u, 2015). Current and potential SME business owners should pay attention to the findings of the study because they can benefit from the strategies. In fact, the importance of group lending, information access, education and professional background as strategies to accessing credit are critically important. Also, I recommend that SME business owners in Kakamega Town and its environs pay attention to the results and share the results with potential future and current SME business owners. I will provide the participants with a two-page summary of the results and findings. Once the research study is approved, I will inform the participants that the complete doctoral research study is available to those who wish to read it and share it with others. My final recommendation is for not only the SME business owners in Kakamega Town but also SME business owners in other parts of 
Kenya to pay attention to the study results, and share the best practices and strategies for improving access to credit for sustainable business growth.

\section{Recommendations for Further Research}

The purpose of this qualitative multiple case study was to explore what strategies some Kenya SME business owners used to access credit to improve company profitability and growth within the past 5 years. The findings indicate some strategies SME business owners used were effective to access credit and sustain their businesses. Semistructured interviews with four SME business owners were conducted to achieve data saturation. Data saturation involves continuing to interview until no new themes emerge. Qualitative researchers often make decisions related to the adequacy of their sample based on the notion of saturation (O'Reilly \& Parker, 2013). This study has two major shortcomings (a) small sample size of participants, and (b) a limited geographical area. This study was limited to four SME business owners located in one town in the Western region of Kenya where business activities may not be as competitive as other regions. Recommendations for further research include involving a larger sample size of participants and a wider geographical area. A study based in a different location, other than Kakamega Town, Kenya is recommended. Conducting quantitative or mixed methods studies could expose a different perspective to the importance of these strategies that SME business owners use to access credit to improve company profitability and growth. I further suggest studies regarding group-lending dynamics as the key strategy for accessing credit. Additional insights by studying the pros and cons of group lending as a strategy for accessing credit by SME business owners may contain useful findings for SMEs. This study based on a qualitative multiple case study design is duplicable 
using other methodologies and designs for further research on the strategies for accessing credit to improve company profitability and growth.

\section{Reflections}

My doctoral study experience provided an opportunity to learn from my study participants. I had the opportunity to interview four SME business owners in Kakamega Town, Kenya, on the strategies used to access credit to improve company profitability and growth within the past 5 years. Conducting the study has broadened my understanding of the doctoral research and increased my understanding of the challenges SME business owners face in accessing credit for their businesses. Gaining access to participants was challenging because of geographical barriers between the potential participants and me. However, I used friends as a strategy to gain access to the potential participants after getting the IRB approval. As the researcher, I followed the interview protocol (Appendix B) to minimize error and researcher bias. I also did not know the SME business owners to mitigate personal bias, and I controlled the reactions to the interview responses to mitigate bias. I had never met the participants or have any preconceived notions regarding the strategies they use to access credit other than the understanding that SME business owners have financial constraints. Interviewing and communicating with the participants of this study has changed my way of thinking about SME business owners. I never realized that SME business owners use several strategies to access credit for their businesses. The participants inspired me with their knowledge regarding the strategies for obtaining credit. The study experience stimulated my interest to meet the four SME business owners after graduation and discuss ways of supporting them to improve their businesses. 


\section{Summary and Study Conclusions}

The purpose of this qualitative multiple case study was to explore what strategies some Kenya SME business owners used to access credit to improve company profitability and growth within the past 5 years. I used methodological triangulation of two data sources to collect data. I conducted semistructured interviews with four SME business owners through Skype to collect the first set of data. Also, I examined each business owner's company documents in the form of profit and loss and cash flow statements as supplementary data. I conducted member checking to confirm the responses of the interview recordings. Member checking allows the researcher to capture the accurate meanings and voice of the interviews (Houghton, Casey, Shaw, \& Murphy, 2013). I achieved data saturation when there were no new themes emerging.

After coding and analyzing the data, four main themes were revealed: (a) group lending, (b) education and professional background of the entrepreneur, (c) information access, and (d) effect of access to credit on the performance of SMEs. I aligned each emergent theme with the literature, the existing body of knowledge and social capital theory. My findings of the study indicated that (a) group lending, (b) information access, and (c) education and professional background of the entrepreneur may be appropriate strategies for accessing credit to improve company profitability and growth. 


\section{References}

Adama, T. Y., \& Nadif, M. (2013). The influence of managers' social capital on SMEs performance and access to external resources in the Moroccan Textile Industry. International Journal of Management and Administrative Sciences, 2, 13-23. Retrieved from http://www.researchgate.net/

Adler, P. S., \& Kwon, S. W. (2002). Social capital: Prospects for a new concept. The Academy of Management Review, 27, 17-40. doi:10.5465/AMR.2002.5922314

Agyei-Mensah, B. K. (2012). Working capital management practices of small firms in the Ashanti Region of Ghana. International Journal of Academic Research in Business and Social Sciences, 2, 567-583. doi:10.2139/ssrn.1596734

Agwu, M. O., \& Emeti, C. I. (2014). Issues, challenges and prospects of small and medium enterprises (SMEs) in Port-Harcourt City, Nigeria. European Journal of Sustainable Development, 3, 101-114. doi:10.14207/ejsd. 2014.v3n1p101

Akomea-Bonsu, C., \& Sampong, F. (2012). Impact of information and communication technologies (ICT) on small and medium scale enterprises (SMEs) in Kumasi Metropolis, Ghana, West Africa. European Journal of Business and Management, 4, 152-159. Retrieved from http://iiste.org/journals/index.php/EJBM/index

Ando, H., Cousins, R., \& Young, C. (2014). Achieving saturation in thematic analysis: Development and refinement of a codebook. Comprehensive Psychology, 3(4), 17. Doi:10.2466/03.CP.3.4

Anyan, F. (2013). The influence of power shifts in data collection and analysis stages: A focus on qualitative research interview. The Qualitative Report, 18(36), 1-9. Retrieved from http://www.nova.edu/ssss/QR/QR18/anyan36.pdf 
Atogenzoya, C. A., Nyeadi, J. D., \& Atiga, O. (2014). The demand for landed property collateral for loan facilities and its impact on small enterprises' investment drive. International Journal of Academic Research in Business and Social Sciences, 4, 79-95. doi:10.6007/IJARBSS/v4-i11/1274

Awino, Z. B. (2013). Strategic planning and competitive advantage of ICT small and medium enterprises in Kenya. Business and Management Horizons, 1, 191-202. doi:10.5296/bmh. v1i1.3942

Belmont Report. (1979). The Belmont Report: Ethical principles and guidelines for the protection of human subjects of research. Retrieved from http://www.hhs.gov

Berger, A. N., Goulding, W., \& Rice, T. (2013). Do small businesses still prefer community banks? Journal of Banking and Finance, 44, 264-278. doi:10.1016/j.jbankfin.2014.03.016

Bhatt, P., \& Altima, L. (2013). How social capital is leveraged in social innovations under resource constraints. Management Decision, 51, 1772-1792. doi:10.1108/MD.01.2013.0041

Boblin, S. L., Ireland, S., Kirkpatrick, H., \& Robertson, K. (2012). Using Stake’s qualitative case study approach to explore implementation of evidence-based practice. Qualitative Health Research, 23, 1267-1275. doi: $10.1177 / 1049732313502128$

Bourdieu, P. (1986). The forms of capital: In handbook of theory and research for the sociology of education. New York: Macmillan.

Bouzahir, B., \& Chakir, A. (2013). Entrepreneurs' access to venture capital in Moroccan's technology-based ventures: An exploratory study of the role of social 
capital. International Journal of Business and Social Science, 4, 144-161.

Retrieved from http://www.ijbssnet.com/

Boyd, B., \& Royer, S. (2012). The suitability of internal versus external successors:

Relevant knowledge types in family business succession. International Journal of Management Practice, 5, 361-382. doi:10.1504/IJMP.2012.050315

Bridge, S. (2013). Reflections on the omission of social capital from enterprise education and business start training. Education and Training, 55, 899-910. doi:10.1108/ET06-2013-0080

Bunyasi, G. N., Bwisa, H., \& Namusonge, G. (2014). Effects of entrepreneurial finance on growth of small and medium enterprises in Kenya. European Journal of Business and Management, 6, 113-123. Retrieved from http://www.iiste.org/journals/index.php/RJFA/article/e/view/12322

Cant, M. C., Erdis, C., \& Sephaso, C. M. (2014). Business survival: The constraints experienced by South African SMEs in the financial sector. International Journal of Academic Research in Business and Social Sciences, 4, 565-579. doi:10.6007/IJARBSS/v4-i10.1255

Carlos, J., \& Pinho, M. R. (2013). The role of relational social capital in examining exporter-intermediary relationships. European Business Review, 25, 553-570. doi:10.1108/EBR-03.2013.0037

Chaimahawong, V., \& Sakulsriprasert, A. (2013). Family business succession and post succession performance: Evidence from Thai SMEs. International Journal of Business and Management, 8, 19-28. doi:10.5539/ijbm. v8n2p19 
Chazdon, S., Allen, R., Horntvedt, J., \& Scheffert, D. R. (2013). Developing and validating University of Minnesota Extension's social capital model and survey. University of Minnesota. Extension. Retrieved from http://conservancy.umn.edu/handle/11299/171657

Chung, C., \& Luo, X. R. (2013). Leadership succession and firm performance in an emerging economy: Successor origin, relational embeddedness, and legitimacy. Strategic Management Journal, 34, 338-357. doi:10.1002/smj.2011

Cope, D. G. (2014). Methods and meanings: Credibility and trustworthiness of qualitative research. Oncology Nursing Forum, 41, 89-91. doi:10.1188/14.ONF.89-91

Damianakis, T., \& Woodford, M. R. (2012). Qualitative research with small-connected communities: Generating new knowledge while upholding research ethics. Qualitative Health Research, 22, 708-718. doi:10.1177/1049732311431444

Devinaga, R., \& Tan, T. M. (2012). Review of Credit Guarantee Corporation of Malaysia (CGCM) initiatives to enhance small and medium enterprises performance. International Journal of Business and Management, 7, 101-111. doi:105539/ijbm. v7n20p101

Donnelly, P. F., Gabriel, Y., \& Ozkazanc-Pan (2013). Untold stories of the field and beyond: Narrating the chaos. Qualitative Research in Organizations and Management: An International Journal, 8, 4-15. doi:10.1108/17465641311327540

Dube, A. P. (2012). A study of group lending in Swaziland: A case of IMBITA Swaziland Women's Finance Trust (Master's thesis). Retrieved from http://scholar.sun.ac.za/handle/100019.1/95611 
Ekpe, I., Razak, R. C., \& Mat, N. B. (2013). The performance of female entrepreneurs:

Credit, training and the moderating effect of attitude towards risk-taking. International Journal of Management, 30, 10-22. Retrieved from http://news.Alacrastore.com/Business-and-Management-Practices/The performance-of-female-entrepreneurs-credit-training-and-the moderating-effectof-attitude-towards-risk-taking-339919475

Gaitho, N. W. (2013). Role of credit reference bureaus on credit access in Kenya: A survey of commercial banks in Kenya. European Scientific Journal, 9, 301-314. Retrieved from http://www.eujournal.org/index.php/esj/article/vileFile/1055/1089

Gambini, A., \& Zazzaro, A. (2013). Long-lasting bank relationships and growth of firms. Small Business Economics, 40, 977. doi:10.1007/s11187-011-9406-8

Gao, S. S., Sung, M. C., \& Zhang, J., (2013). Risk management capability building in SMEs: A social capital perspective. International Small Business Journal, 31, 677-700. doi:10.1177/0266242611431094

Gichuki, J. A. W., Njeru, A., \& Ondabu, I. T. (2014). Challenges facing micro and small enterprises in accessing credit facilities in Kangemi Harambee Market in Nairobi City County, Kenya. International Journal of Scientific and Research Publications, 4(12), 1-25. Retrieved from http://www.ijrp.org/research-paper12/4/ijrsp-p3614.pdf

Glaser, J., \& Laudel, G. (2013). Life with and without coding: Two methods for earlystages data analysis in qualitative research aiming at causal explanations. Forum: Qualitative Social Research, 14(2), 1-38. Retrieved from http://www.qualitativeresearch.net/index.php/fqs/article/view/1986 
Goffin, K., Raja, J. Z., Claes, B., Szwejczewski, M., \& Martinez, V. (2012). Rigor in qualitative supply chain management research: Lessons from applying repertory grid technique. International Journal of Physical Distribution and Logistics Management, 42, 804-827. doi:10.1108/09600031211269767

Granovetter, M. (1983). The strength of weak ties: A network theory revisited. Sociological Theory, 1, 201-233. Retrieved from http://soc.uc.sb.edu/faculty/friedkin/syllabi/soc148/Granovetter\%201983.pdf

Guo, D., \& Jiang, K. (2013). Venture capital investment and the performance of entrepreneurial firms: Evidence from China. Journal of Corporate Finance, 22, 375-395. doi: 10.1016/j.jcorpfin.2013.07.001

Hanifan, L. J. (1916). The rural school community center. Annals of the American Academy of Political and Social Science, 67, 130-138. Retrieved from http//www.jstor.org/stable/1013498? seq=1\#page_scan_table_contents

Hanna, P. (2012). Using internet technologies (such as Skype) as a research medium: A research note. Qualitative Research, 12, 239-242. doi:10.1177/1468794111426607

Harper, M., \& Cole, P. (2012). Member checking: Can benefits be gained similar to group therapy? The Qualitative Report, 17, 510-517. Retrieved from http://www.nova.edu/ssss/QR/QR17-2/harper.pdf

Hassan, A. (2014). The challenge in poverty alleviation: Role of Islamic microfinance and social capital. Humanomics, 30, 76-90. doi:10.1108/H.10.2013.0068

Hassan, I. B., \& Mugambi, F. (2013). Determinants of growth for women-owned and operated enterprises: The case of Garissa, Kenya. International Journal of 
Business and Commerce, 2, 45-55. Retrieved from http://ijbc.net.com/2.7/IJBC13-12801.pdf

Hazzan, O., \& Nutov, L. (2014). Teaching and learning qualitative research: Conducting qualitative research. The Qualitative Report, 19(24), 1-29. Retrieved from http://nsuworks.nova.edu/tqr/vol19/iss24/3

Houghton, C., Casey, D., Shaw, D., \& Murphy, K. (2013). Rigor in qualitative case study research. Nurse Researcher, 20, 12-17. doi:10.7748/2013.03.20.12.326

Ijaza, A. K., Mwangi, S. W., \& Ng'etich, K. A. (2014). Challenges faced by the women enterprise fund in Kenya: A survey of Hamisi constituency, Vihiga County, Kenya. Research on Humanities and Social Studies, 4, 20-28. Retrieved from http://www.iiste.org/journals/index.php/RHSS/article/viewFile/14316/14624

Irvine, A., Drew, P., \& Sainsbury, R. D. (2013). Am I not answering your questions properly? Clarification, adequacy and responsiveness in semistructured telephone face-face interviews. Qualitative Research, 13, 87-106. doi:10.1177/1468794112439086

Jagongo, A. (2012). Venture capital (VC): The all-important MSMEs financing strategy under neglect in Kenya. International Journal of Business and Social Science, 3, 234-340. Retrieved from http:/ijbssnet.com/journals/vol_3_NO_21_November_2012/24.

Jonsson, S., \& Lindbergh, J. (2013). The development of social capital and financing of entrepreneurial firms: From financial bootstrapping to bank funding. Entrepreneurship Theory and Practice, 37, 661-686. doi:10.1111/j.15406520.2011. 00485.x 
Jaoua, F., \& Radouche, T. (2014). The moderating role of leader skills on the relationship between strategic management and global performance: An empirical study. International Business Research, 7, 59-72. doi:10.5539/. ibr. v7n8p59

Kaczynski, D., Salmona, M., \& Smith, T. (2013). Qualitative research in finance. Australian Journal of Management, 39, 127-135. doi:10.1177/0312896212469611

Kagwathi, G.S., Kamau, J. N., Njau, M. M., \& Kamau, S. M. (2014). Risks faced and mitigation strategies employed by small and medium enterprises in Nairobi, Kenya. IOSR Journal of Business and Management, 16 (4), 1-11. Retrieved from http://www.iosrjournals.org/iosr-jbm/papers/vol16-issue4/version5/A016450111.pdf

Kang, E., Zardkoohi, A., Paetzold, R. L., \& Fraser, D. (2013). Relationship banking and escalating commitments to bad loans. Small Business Economics, 40, 899-910. doi:10.1007/s11187-011-9392.x

Kansikas, J., Laakonen, A., Sarpo, V., \& Kontinen, T. (2012). Entrepreneurial leadership and familiness of resources for strategic entrepreneurship. International Journal of Entrepreneurial Behavior and Research, 18, 141-158.

doi: $10.1108 / 13552551211204193$

Karanja, J. G. (2012). Role of succession planning on survival of small and medium family enterprises after retirement/death of the first generation entrepreneurs in Kenya. Prime Journal of Business Administration and Management, 2, 788-802. Retrieved from http://primejournal.org/BAM/pdf/2012/dec/karanja/pdf Kariuki, C. N. N. (2015). Factors affecting development of strategic plans in SMEs: A case study of clothing shops in Nairobi, Kenya (Doctoral dissertation, United 
States International University-Africa). Retrieved from http://erepo.usiu.ac.ke/handle/123456789/629

Kilele, A. K., Nduruhu, D., \& Kimani, M. (2015). Determinants of group loans uptake at the Youth Enterprise Development Fund: A survey of Nakuru West Constituency, Kenya. International Journal of Economics, Commerce and Management, 3, 820835. Retrieved from http://hdi.handle.net/123456789/597

Kira, A. R. (2013). Determinants of financing constraints in East African countries' SMEs. International Journal of Business and Management, 8, 49-68. doi:10.5539/ijbm. v8n8p49

Kiragu, E. M., \& Sakwa, M. (2013). Effect of group lending mechanism enterprise development of rural women in Kenya. A survey of Kenyenya District, Kisii County, Kenya. Interdisciplinary Journal of Contemporary Research in Business, 4, 556-584. Retrieved from http://journal-archives31.web.coom/556-584.pdf

Kisaka, E. S., \& Mwewa, N. M. (2014). Effects of micro-credit, micro-savings and training on the growth of small and medium enterprises in Machakos County, Kenya. Research Journal of Finance and Accounting, 5, 43-49. Retrieved from http://www.iiste.org/journals/index.php/RJFA/article/view/12305

Kontinen, T., \& Ojala, A. (2012). Social capital in the international operations of family SMEs. Journal of Small Business and Enterprise Development, 19, 39-55. doi: $10.1108 / 14626001211196398$

Koropp, C., \& Grichnik, D. (2013). Succession financing in family firms. Small Business Economics, 41, 315-334. doi:10.1007/s11187-012.-9442-z 
Kung'u, G. K. (2015). Factors influencing small and medium enterprises' access to funding in Kenya: A case study of Westlands Division. Available at ssrn.com/abstract $=2665041$

Lach, D. (2014). Challenges of interdisciplinary research: Reconciling qualitative and quantitative methods for understanding human-landscape systems. Environmental Management, 53, 88-93. doi:10.1007/s00267-013-0115-8

Light, I., \& Dana, L. P. (2013). Boundaries of social capital in entrepreneurship. Entrepreneurship Theory and Practice, 37(3), 1-22. doi:10.1111/.etapp.12016

Lu, H., Feng, S., Trienekens, J. H., \& Omta, S. W. F. (2012). Networks strength, transaction-specific investments, interpersonal trust, and relationship satisfaction in Chinese agri- food SMEs. China Agricultural Economic Review, 4, 363-378. doi:10.10.1108/1756137121126374

Lussier, R. N. (2012). Family businesses' succession planning: A seventy-country comparison. Journal of Small Business and Enterprise Development, 19, 7-19. doi:10.1108/14626001211222559

Maenpaa, I. (2012). Drivers of cross-sectoral cross-buying behavior among business customers.

International Journal of Bank Marketing, 30, 193-217. doi:10.1108/02652321211222559

Makena, P., Kubaison, S., \& Njati, C. I. (2014). Challenges facing women entrepreneurs in accessing business finance in Kenya: A case of Ruiru Township, Kiambu County, Kenya. IOSR Journal of Business and Management, 16, 83-91. Retrieved from http://iosrjournals.org/iosr-jbm/papers/vol16-issue4/version-3/Mo16438391 
Marshall, B., Cardon, P., Poddar, A., \& Fontennot, R. (2013). Does sample size matter in qualitative research? A review of qualitative interviews in IS research. Journal of Computer Information Systems, 54, 11-21. Retrieved from http://iacis.org/jcis/articles/JCIS54-2.pdf

Marton, A. (2013). Purposive selection and the quality of qualitative IS research. Paper presented at the Thirty-Fourth International Conference on Information Systems, Milan. Abstract retrieved from http://forknings.basen.deff.dk/share.external?sp=Sec82d5c6-6b6a-424f-b371a5b346067098\&sp=Scbs

Mayoh, J., \& Onwuegbuzie, A. J. (2015). Toward conceptualization of mixed methods: Phenomenological research: Journal of Mixed Methods Research, 9, 91-107. doi: $10.1177 / 1558689813505358$

Mbugua, J. K., Mbugua, S. N., Wangoi, M., Ogada, J. O., \& Kariuki, J. N. (2013). Factors affecting the growth of micro and small enterprises: A case of tailoring and dressmaking enterprises in Eldoret. International Journal of Business and Social Science, 4, 285-293. Retrieved from http:ijbssnet.com/journals/vol_4_NO_5_May_2013/34.pdf

Memba, S. F., Gakure, W. R., \& Karanja, K. (2012). Venture capital (VC): Its impact on growth of small and medium enterprises in Kenya. International Journal of Business and Social Science, 3, 32-38. Retrieved from http://vc4Africa.biz/wpcontent/uploads/2012/04/vc-kenya-report.pdf 
Mendes, S., Serrasqueiro, Z., \& Nunes, P. M. (2014). Investment determinants of young and old Portuguese SMEs: A quantile approach. Business Research Quarterly, 17, 279-291. doi: 10.1016/j.brq.2013.03.001

Mitchelmore, S., \& Rowley, J. (2013). Growth and planning strategies within women-led SMEs. Management Decision,51, 83-96. doi:10.1108/00251741311291328

Moustakas, C. (1994). Phenomenological research design. Thousand Oaks, CA: Sage Publications, Inc.

Moyi, E. D. (2013). Credit and employment growth among small enterprises in Kenya. International Journal of Business and Economics Research, 2, 69-76. doi:10.11648/j.ijber.20130203.14

Musamali, M. M., \& Tarus, D. K. (2013). Does firm profile influence financial access among small and medium enterprises in Kenya? Asian Economic and Financial Review, 3, 714-723. Retrieved from http://aessweb.com/pdf-files/aefr/\%20714723

Mwangi, M., Gongera, G. E., Mindila, R., Nyakwara, S., Ongeri, J., \& Okeyo, H.N. (2013). An evaluation of financing and development of small and medium enterprises in Mombasa County, Kenya. European Journal of Business and Management, 5, 16-25. Retrieved from http://www.iiste.org/journals/index.php/EJBM/article/download/6163/6292

Mwangi, I., W. \& Ouma, S. A. (2012). Social capital and access to credit in Kenya. American Journal of Social and Management Sciences, 3, 8-16. Retrieved from http://www.scihub.org/AJSMS/PDF/2012/1/AJSMS-3-1-8-16.pdf 
Mwangi, N., Shisia, A., Mwai, L., \& Okibo, W. B. (2014). Assessment of micro financial institution funding on the performance of small and medium enterprises in Murang'a County, Kenya. European Journal of Business and Management, 6, 3342. Retrieved from http://iiste.org/journals/index.php/EJBM/article/viewFile/14930/15664

Mwarari, M. M. (2013). Factors influencing listing of Kenyan SMEs in the securities market for capital raising opportunities. European Journal of Management Sciences and Economics, 1, 99-115. Retrieved from http://www.marysam.co.uk/uploads/1/4/7/14075053/abstract-factors-influencinglisting-of kenyan-smes.pdf

Mwaura, A. T. W., Gathenya, J. W., \& Kihoro, J. M. (2015). Influence of entrepreneurial group dynamics on the performance of women owned enterprises in Kenya. International Journal of Academic Research in Business and Social Sciences, 5, 206-218. doi:10.6007/IJARBSS/v5-i10/1869

Mwobobia, F. M. (2012). The challenges facing small-scale women entrepreneurs: A case of Kenya. International Journal of Business Administration, 2, 112-121. doi:10. 5430.ijba. v3n2p112

Nahapiet, J., \& Ghoshal, S. (1998). Social capital, intellectual capital, and the organizational advantage. Academy of Management Review, 23, 242-266. Retrieved from http://staffweb.hkbu.edu.hk.vwschow/lectures/ism3620/rp01.pdf Napoli, F. (2012). The effects of corporate governance processes of strategy change and value creation in small and medium-sized firms: A study of family-owned firms in Italy. International Journal of Management, 29, 232-260. Retrieved from 
http://www.questia.com/library/journal/1p3-2762924/01/the-effects-of-corporategovernance-processes-of-strategy

Narteh, B. (2013). SME bank selection and patronage behavior in the Ghanaian banking industry. Management Research Review, 36, 1061-1080. doi:10.1108/MRR-062012-0147

Naveen, K. K. (2012). Dynamic incentives in microfinance group lending: An empirical analysis of progressive lending mechanism. Sage Open, 1-9. doi: $10.1177 / 21582244012444280$

Nawai, N., \& Shariff, M. N. M. (2013). Loan repayment problems in microfinance programs that use individual lending approach: A qualitative analysis. Journal of Transformaitve Entrepreneurship, 1(2), 93-99. doi:10.14239/JTE.2013.01203

Ndagijimana, J.P., \& Oketch, T. C. (2014). Determinants of working capital management practices in small and medium enterprises in Nairobi, Kenya. International Journal of Business and Social Science, 5, 160-164. Retrieved from http://ijbssnet.com/vol_5_no_november_2014/20.pdf

Nguyen, N., \& Luu, N. (2013). Determinants of financing pattern and access to formalinformal credit: The case of small and medium- sized enterprises in Vietnam. Journal of Management Research, 5, 240-259. doi:10.5296/jmr. v5i2.3266

Njeru, E. K. (2014). The effect of credit financing on profitability of small and mediumsized enterprises in Nairobi County, Kenya (Master's thesis). Retrieved from http://erepository.uonbi.ac.ke/handle/1295/77581

Njeru, A. W., Namusonge, G. S., \& Kihoro, J. M. (2012). Size as a determinant of choice of source of entrepreneurial finance for small and medium-sized enterprises in 
Thika District, Kenya. International Journal of Business and Social Science, 3, 53-58. Retrieved from http://www.ijbssnet.com/journals/vol_3_16_special_August_2012/6.pdf

Njeru, A. W., Nyangaresi, W. M., \& Waithaka, G. N. (2013). Influence of information availability on the choice of entrepreneurial source of finance. International Journal of Business and Social Science, 4, 256-261. Retrieved from http://ijbssnet.com/journals/vol_4_No_9_August_2013/25.pdf

Nkonge, B. K. (2013). Challenges faced by small and medium enterprise suppliers when bidding for tenders: A case study of Thika District, Kenya. International Journal of Academic Research in Business and Social Sciences, 3, 194-220. doi:10.6007/IJARBSS/v3-i12/426

Norqvist, M., Wennberg, K., Bau, M., \& Hellerstedt, K. (2013). An entrepreneurial process perspective on succession in family firms. Small Business Economics, 40, 1087-1122. doi:10.1007/s11187-012-9466-4

Nyamboga, T. O., Nyamweya, B. O., Abdi, A. M., Njeru, F., \& Gongera, E. G. (2014). An assessment of financial literacy on loan repayment by small and medium entrepreneurs in Ngara, Nairobi, Kenya. Research Journal of Finance and Accounting, 5, 181-192. Retrieved from http://www.iiste.org/journals/index.php/RJFA/article/view/13594

Okoth, O. S., Okelo, S., Aila, F., Awiti, A. O., Onyango, M., Ogutu, M., Odera, O. (2013). Effect of the Youth Enterprise Development Fund on youth enterprises in Kenya. International Journal of Advances in Management and Economics, 2(1), 111-116. Retrieved from http://www.managementjournal.info 
Omar, N. A., Nazri, M. A., \& Wel, C.A. C. (2014). Entrepreneurial training of lowincome women micro enterprises in the service sector in Malaysia: Understanding the problems and challenges. Journal of Social and Development Sciences, 5, 245-257. Retrieved from http://researchgate.net/profile/Nor_Asiah_Omar/publication/270957663Entrepreneurial_Training_of_low_income_women_micro_entreprises_in_the_ser vice_sec

Ongachi, R. N., \& Bwisa, H. M. (2013). Factors influencing growth of women-owned micro and small enterprises: A survey of Kitale Municipality, Kenya. International Journal of Academic Research in Business and Social Sciences, 3, 182-196. Retrieved from http://hrmars.com/hrmars_papers/Factors_Influencing _Growth_of_Women_Owned_micro_and_small_enterprises.pdf

Ong'injo, F. O. (2014). Analysis of factors affecting accessibility of credit facilities among the small and medium enterprises: A case study of Siaya Town, Kenya (Bachelor's dissertation, University of Nairobi). Retrieved from http://erepository.uonbi.ac.ke/handle/11295/72298

Onyango, K. A., \& Achieng, M. R. (2013). Financial constraints of small and medium enterprises: A case study of Kisumu County, Kenya. International Journal of Marketing and Technology, 3, 241-252. Retrieved from http://www.indianjournals.com/ijor.aspx?target=ijor.ijmt\&volume=3\&issue=7arti cle $=016$ 
O’ Brien, B. C., \& Reed, D. A. (2014). Standards for reporting qualitative research: A synthesis of recommendations. Academic Medicine, 89, 1245-1261. doi:10.1097/IACM.0000000000000388

Onwuegbuzie, A. J., \& Byers, V. T. (2014). An exemplar for combining the collection, analysis, and interpretations of verbal and non-verbal data in qualitative research. International Journal of Education, 6, 183-246. doi:10.5296/ije. v6i1.4399

Ooi, Y. K., \& Ahmad, S. (2012). A study among universities in business start-ups in Malaysia: Motivations and obstacles to become entrepreneurs. International Journal of Business and Social Science, 3, 181-192. Retrieved from http://ijbssnet.com/journals/vol_3_NO_October_2012/20.pdf

Oluwatayo, J. A. (2012). Validity and reliability issues in educational research. Journal of Educational and Social Research, 2, 391-400. doi:10.5901/jesr. 2012.v2n2.391

O’Reilly, M., \& Parker, N. (2012). Unsatisfactory saturation: A critical exploration of the notion of saturated sample sizes in qualitative research. Qualitative Research, 13, 190-197. doi:10.1177/1468794112446106

Osoro, K., \& Muturi, W. (2014). The effects of financial institutions intervention on the growth of small enterprises in Kenya: A survey of public transportation services in Kisii Municipality, Kenya. Developing Country Studies, 4, 57-72. Retrieved from http://iiste.org/journals/index.php/DCS/article/view/17106/17465

Ouma, C. O., \& Rambo, C. M. (2013). Effects of access to microcredit on the growth of women-owned small and medium enterprises in the Central Business District of Kisumu: The case of Kenya Women Finance Trust. Global Conference on 
Business and Financial Proceedings, 8(1), 1-6. Retrieved from http://erepository.uonbi.ac.ke/handle/11295/35690

Pearson, A. W., Carr, J. C., \& Shaw, J. C. (2008). Toward a theory of familiness: A social capital perspective. Entrepreneurship Theory and Practice, 32, 949-969. doi:10.1111/j.1540-6520.2008. 00265.x

Peredaryenko, M. S., \& Krauss, S. E. (2013). Calibrating the human instrument: Undertaking the interviewing experience of novice qualitative researchers. The Qualitative Report, 18(85), 1-17. Retrieved from http://www.nova.edu/ssss/QR/QR18/peredaryenko85.pdf

Petty, N. J., Thompson, O. P., \& Stew, G. (2012). Ready for a paradigm shift? Part 2: Introducing qualitative research methodologies and methods. Manual Therapy, 17, 378-384. doi:10.1016/j.math.2012.03.004

Poulis, K., Poluis, E., \& Plakoyianak, E. (2013). The role of context in case study selection: An international business perspective. International Business Review, 22, 304-314. doi:10.1016/j.ibusrev.2012.04.003

Prasad, S., Tata, J., \& Guo, X. (2012). Sustaining small businesses in the United States in times of recession: Role of supply networks and social capital. Journal of Advances in Management Research, 9, 8-28. doi:10.1108/09727981211225626

Putnam, R. D. (1995). Bowling alone: America's declining social capital. Journal of Democracy, 6, 65-78. doi:10.1353/jod.1995.0002

Quaye, I., \& Smith, A. (2014). Assessing alternative sources of financing for small and medium enterprises in Ghana: Case study of savings and loans companies in the 
Greater Accra Region of Ghana. International Journal of Advancements in Research and Technology, 3, 123-136. Retrieved from http://www.ijoart.org/docs/ Rambo, C. M. (2012). Risk factors influencing the survival of strategic alliances among small and medium enterprises in Kenya: Evidence from Kisumu District, Kenya. Global Conference on Business and Finance Proceedings, 7, 419-431. Retrieved from http://www.researchgate.net/profile/Bamini_KPD_Balakishan/publication/265787 130_The_Impact_of_Brand_Personality_on_Brand_Preference_and_Loyalty_A_ Study

Rauch, A., Doorn, R. V., \& Hulsink, W. (2014). A qualitative approach to evidencebased entrepreneurship: Considerations and an example involving business clusters. Entrepreneurship Theory and Practice, 333-368. doi:10.1111/etap.12093

Robinson, O. C. (2013). Sampling in interview-based qualitative research: A theoretical and practical guide. Qualitative Research in Psychology, 11(1), 25-41. doi:10.1080/14780887.2013.801543

Rowley, J. (2012). Conducting research interviews. Management Research Review, 35, 260-271. doi:10.1108/01409170210782990

Sandada, M., Pooe, D., \& Dhurup, M. (2014). Strategic planning and its relationship with business performance among small and medium enterprises in South Africa. International Business and Economics Research Journal, 13, 659-669. Retrieved from http://www.cluteinstitute.com/ojs/index.php/IBER/article/view/8602 
Sandhu, N., Hussan, J., \& Matlay, H. (2012). Entrepreneurship education and training needs of family businesses operating in the agricultural sector of India. Education and Training, 54, 727-743. doi:10.1108/00400911211274855

Sarpong, K. A. M., \& Arthur, J. K. (2013). Analysis of data cleansing approaches regarding dirty data: A comparative study. International Journal of Computer Applications, 76, 14-18. doi:10.5120/13258-0736

Schulman, M. D., \& Anderson, C. (1999). The dark side of the force: A case study of restructuring and social capital. Rural Sociology, 64, 351-372. doi:10.1111/j.1549-0831.1999.00357

Shi, Y. (2012). An investigation of the role of professionalism in helping new firms obtain venture capital and angel investment (Master's thesis). Retrieved from http//www. Ruor.uottawa.ca/handle/10393/25475

Shikimi, M. (2013). Do firms benefit from multiple banking relationships? Evidence from small and medium-sized firms in Japan. International Economic Policy, 10, 2127-157. doi:10.1007/5/0368-011-0996-x

Simen, S. F. (2013). Roles of networks and social capital in the success of international: Case of the Chinese merchants in Senegal. Journal of Management Research, 5, 128-144. doi:10.5296/jmr. v5i44090

Simon, M. K., \& Goes, J. (2013). Dissertation and scholarly research: Recipes for success. Seattle, WA: Amazon.com, Inc.

Smith, E. (2012). Getting in through the front door: The first hurdle of researching in companies. International Journal of Training Research, 10, 153-163. Retrieved from http://eric.ed.gov/?id=EJ992385 
Snyder, C. (2012). A case study of a case study: Analysis of a robust qualitative research methodology. The Qualitative Report, 17, (26), 1-21. Retrieved from http://www.nova.edu/ssss/QR/QR17/snyder.pdf

Srivastava, S. K. (2012). Managerial implications from Indian case studies on e-reverse auctions. Business Process Management, 18, 513-531. doi: $10.1108 / 1463715121123268$

Stam, W., Arzlanian, S., \& Elfring, T. (2013). Social capital and small firm performance: Meta-analysis of contextual and methodological moderators. Journal of Business Venturing, 29, 152-173. doi: 1016/j.jbusvent.2013.01.002

Standa, F. N. (2013). The types of small businesses and communication strategies employed by entrepreneurs in Eldoret Town, Kenya. Journal of Emerging Trends in Economics and Management Sciences, 4, 243-252. Retrieved from http://reference.sabinet.co.za/sa-epublications_article/sl-jetems_v4-n2-a18

Stephens, S. (2013). Building an entrepreneurial network: The experiences of immigrant entrepreneurs. Journal of Enterprising Communities: People and Places in the Global Economy, 7, 223-244. doi:10.1108/JEC-12.2011.0026

Tufford, L., \& Newman, P. (2012). Bracketing in qualitative research. Qualitative Social Work, 11, 80-96. doi:10.1177/1473325010368316

Wachilonga, L. W. (2013). Firm size and capital structure decisions: Evidence from hotels and lodging SMEs in Eldoret Municipality, Kenya. International Journal of Academic Research in Business and Social Sciences, 3, 561-577. doi:10.6007/IJARBSS/v3-i8/183 
Waithaka, T., Marangu, W. N., \& Ng'ondu, C. N. (2014). Entrepreneurial development by microfinance institutions effect on the growth of micro and small enterprises in Nairobi Central Business District: A case of Jitegemea Credit Scheme, Nairobi, Kenya. European Journal of Business and Management, 6, 177-186. Retrieved from http://iiste.org/journals/index.php/EJBM/article/view/12705

Walker, G., Kogut, B., \& Shan, W. (1997). Social capital, structural holes and the formation of an industry network. Organizational Science, 8, 109-125. doi:10.1287/8.2.109

Wambua, F. M., \& Mugambi, F. (2013). The effect of multiple banking on the performance of small and medium enterprises in Mombasa, Kenya. International Journal of Economics and Finance, 1(5), 161-184. Retrieved from http://www.ijsse.org/article/ijsse_v1_i5_161_184.pdf

Wanambisi, A. N., \& Bwisa, H. M. (2013). Effects of microfinance lending on business performance: A survey of micro and small enterprises in Kitale Municipality, Kenya. International Journal of Academic Research in Business and Social Sciences, 3, 56-67. doi:10.6007/IJARBSS/v3-i7/9

Whiteley, A. (2012). Supervisory conversations on rigor and interpretive research. Qualitative Research Journal, 12, 251-271. doi:10.1108/14439881211248383

Wiles, R., \& Boddy, J. (2013). Introduction to the special issue: Research ethics in challenging contexts. Methodological Innovations Online, 8(2), 1-5. doi:10.4256/mio.2013.009 
Wiles, R., Coffey, A., Robinson, J., \& Heath, S. (2012). Anonymisation and visual images: Issues of respect, voice and protection. International Journal of Social Research Methodology, 15(1), 41-53. doi:10.1080/13645579.2011.564423

Woolcock, M., \& Narayan, D. (2000). Social capital: Implications for development theory, research, and policy. World Bank Research Observer, 15, 225-249. doi:10.1093/wbro/15.2.225

Xiang, D., \& Worthington, A. C. (2013). The impact of Government financial assistance on SMEs in Australia during the GFC (Finacial Report No. 201307). Griffith University, Department of Accounting, Finance and Economics. Retrieved from http://www.120.secure.griffith.edu.au/research/file27bd2613-072a-42dc8f793259156dded0/1/2013-07-the -impact-of-government-financial-assistance-onSMEs-in-Australia-during-the-GFC.pdf

Yesseleva, M. (2013). Professional advice and its possible effect on small and mediumsized enterprises' access to external debt finance in Australia. Global Business and Management Research: An International Journal, 5, 24-31. Retrieved from http://www.gbmr.ioks.com/pdf/vol.\%205\%20no.\%201/3-Yesseleva\%202013.pdf

Yildrim, H. S., Akci, Y., \& Eksi, I. H. (2013). The effect of firm characteristics in accessing credit for SMEs. Journal of Financial Services Marketing, 18, 40-52. doi: $10.1057 /$ fsm. 2012.28

Yin, K. R. (2014). Case study research design and methods $\left(5^{\text {th }}\right.$ ed.). Thousand Oaks, CA: Sage. 
Zohrabi, M. (2013). Mixed methods research: Instruments, validity, reliability and reporting findings. Theory and Practice in Language Studies, 3, 254-264. doi: $10.4304 /$ tpls.3.2.254-264 


\section{Appendix A: Interview Questions}

The following interview questions are for this qualitative multiple case study.

Questions 1-6 concept questions, and Question 7 is the wrap-up question.

1.What strategies do you use to access credit for your business?

2.What are the main challenges to accessing credit for your business?

3. How does your relationship with other SME business owners help you obtain credit

for your business?

4. How would you describe your relationship with banks?

5. How does access to information help you obtain credit for your business?

6. How does accessibility to credit affect the performance of your business?

7.What else would you like to share about your experience of how to access credit for your business? 


\section{Appendix B: Interview Protocol}

1. Introduce self to the participant(s) via Skype.

2. Go over contents of the form, answer questions, and concerns of participant(s).

3. Turn on the audio recording device.

4. Follow the procedure to introduce participant(s) with a pseudonym and coded identification; note the date and time.

5. Begin interview with question \#1; follow through to the final question.

6. Follow up with additional questions.

7. End interview sequence; discuss member-checking with the participant(s) via Skype.

8. Thank the participant(s) for their part in the study. Reiterate contact numbers for follow-up questions and concerns from participants.

9. End protocol. 